OECD Social, Employment and Migration Working Papers No. 33

\title{
Alternative Measures of Well-Being
}

\section{Romina Boarini,}

Asa Johansson, Marco Mira d'Ercole

https://dx.doi.org/10.1787/713222332167 


\section{Alternative Measures of Well-Being}

Romina Boarini, Asa Johansson and Marco Mira d’Ercole

\section{3}


Organisation de Coopération et de Développement Economiques

Organisation for Economic Co-operation and Development

17-Feb-2006

DIRECTORATE FOR EMPLOYMENT, LABOUR AND SOCIAL AFFAIRS

English text only

EMPLOYMENT, LABOUR AND SOCIAL AFFAIRS COMMITTEE

OECD SOCIAL, EMPLOYMENT AND MIGRATION WORKING PAPERS NO. 33

ALTERNATIVE MEASURES OF WELL-BEING

Romina Boarini, Asa Johansson and Marco Mira d'Ercole

JEL Classification: I31, D31, D6, J22 


\title{
DIRECTORATE FOR EMPLOYMENT, LABOUR AND SOCIAL AFFAIRS
}

\author{
http://www.oecd.org/els
}

\section{OECD SOCIAL, EMPLOYMENT AND MIGRATION WORKING PAPERS}

\author{
http://www.oecd.org/els/workingpapers
}

This series is designed to make available to a wider readership selected labour market, social policy and migration studies prepared for use within the OECD. Authorship is usually collective, but principal writers are named. The papers are generally available only in their original language - English or French - with a summary in the other.

Comment on the series is welcome, and should be sent to the Directorate for Employment, Labour and Social Affairs, 2, rue André-Pascal, 75775 PARIS CEDEX 16, France.

The opinions expressed and arguments employed here are the responsibility of the author(s) and do not necessarily reflect those of the OECD

\section{Applications for permission to reproduce or translate all or part of this material should be made to:}

\author{
Head of Publications Service \\ OECD \\ 2, rue André-Pascal \\ 75775 Paris, CEDEX 16 \\ France
}

Copyright OECD 2006 


\section{ACKNOWLEDGEMENTS}

Romina Boarini is currently a Young Professional in the OECD Economics Department. At the time of writing, she was in the Directorate for Employment, Labour and Social Affairs. Asa Johansson is an Administrator in the OECD Economics Department. Marco Mira d'Ercole is a Senior Administrator in the OECD Directorate for Employment, Labour and Social Affairs. Special thanks to François Lequiller, head of the OECD National Accounts Division, for his very helpful comments and suggestions on previous drafts of the paper. The authors also wish to thank Sven Blöndal, Jorgen Elmeskov and Mike Feiner of the OECD Economics Department; John P. Martin, Martine Durand and Mark Pearson of the OECD Directorate for Employment Labour and Social Affairs; Enrico Giovannini of the OECD Statistics Directorate; Mark Fleurbaey, Centre National de la Recherche Scientifique; and Andrew Clark, ParisJourdan Science Économique and Centre National de la Recherche Scientifique. Errors are the responsibilities of the authors alone. The views expressed in this paper are those of the authors, and do not necessarily reflect those of the OECD or of its member countries. 
TABLE OF CONTENTS

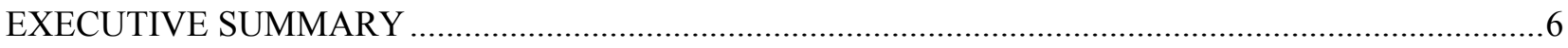

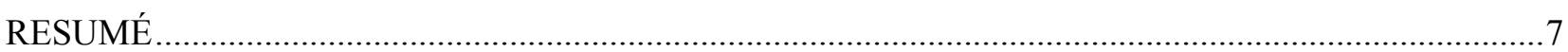

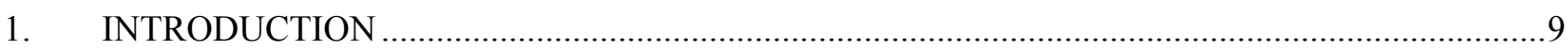

2. MONETARY MEASURES OF ECONOMIC RESOURCES ……...............................................

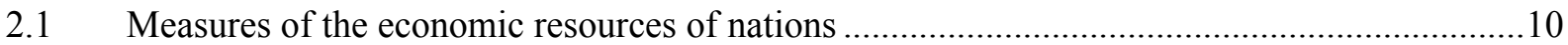

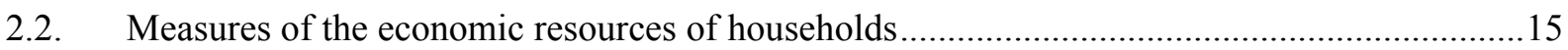

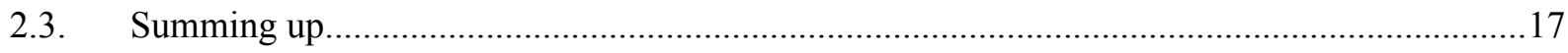

3. THE INFLUENCE OF OTHER FACTORS ON WELL-BEING .................................................

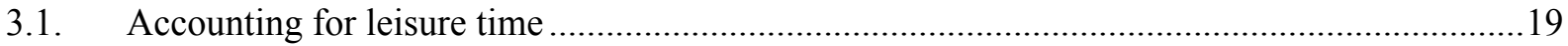

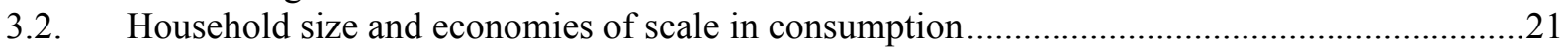

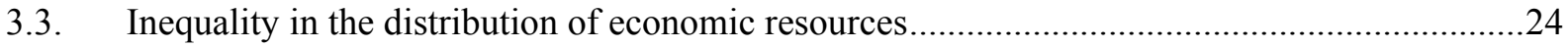

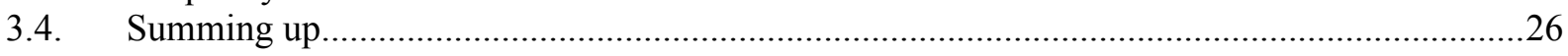

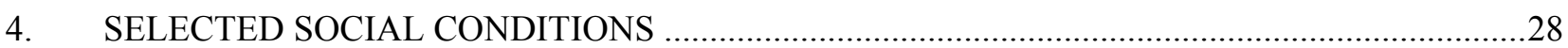

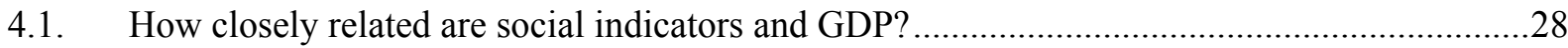

4.2. Aggregation of social indicators into synthetic indexes of well-being .....................................30

5. SUBJECTIVE MEASURES OF HAPPINESS AND LIFE-SATISFACTION …............................33

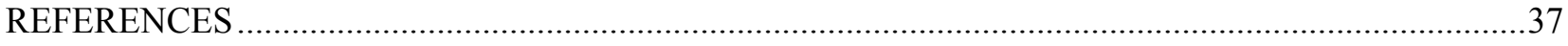

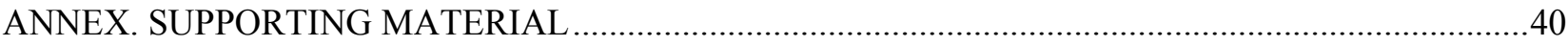

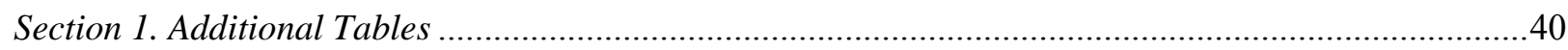

Section 2. Accuracy of international comparisons of GDP .....................................................................46

Section 3. Currency benchmarks and the use of Purchasing Power Parities ............................................47

Section 4. Adjusting national account aggregates for leisure time .........................................................49

Section 5. Synthetic measures of well-being: normalisation and weighting of four categories of OECD

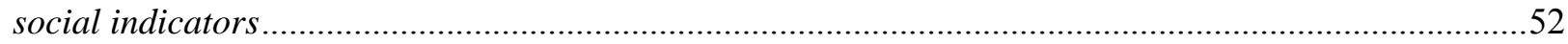

\section{Boxes}

Box 1. Some insights on well-being provided by the economic literature ……..................................... 9

Box 2. The measurement of government production in national accounts..............................................10

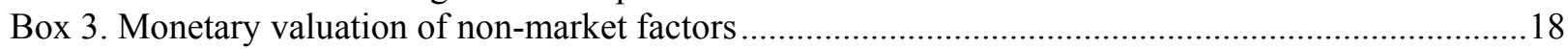

Box 4. Differences between national accounts and survey-measures of household income ....................23

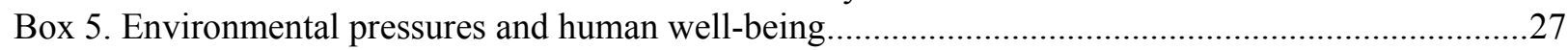

Box 6. Statistical validity of subjective measures of life satisfaction......................................................33

Box 7. Adaptation, social comparisons and subjective life-satisfaction .................................................36 


\section{Tables}

Table A.1. Impact of changes in income distribution on the growth of real per capita household disposable income 40

Table A.2. Correlation coefficients among social indicators within each of the four domains................... 41

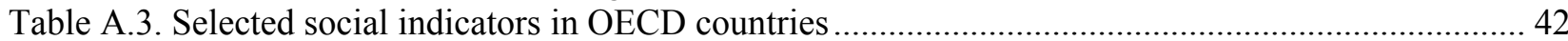

Table A.4. Composite measures of well-being in selected OECD countries ............................................ 43

Table A.5. Gap in GDP per capita relative to the United States based on PPPs at current and constant

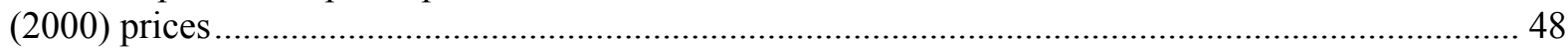

Table A.6. Impact of changes in the amount of leisure time of workers on the annual growth of real per capita GDP

\section{Figures}

Figure 1. GDP and GNI per capita 2003, US\$ current prices and current PPPs 11

Figure 2. Average annual growth in real GDP and real GNI per capita, 1994-2003 ................................ 12

Figure 3. GDP and NDP per capita, 2003, US\$ current prices and current PPPs ..................................... 13

Figure 4. Average annual growth in real GDP and real NDP per capita, 1994-2003 ................................ 13

Figure 5. GDP and NNI per capita, in US\$ current prices and PPPs, 2003 ........................................... 14

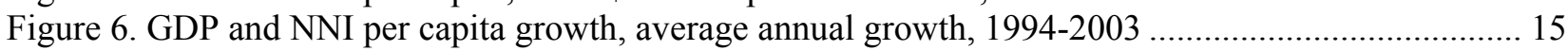

Figure 7. Consumption, actual consumption and GDP per capita, 2003 ............................................ 16

Figure 8. Real household's disposable income, real final consumption expenditure and real GDP per capita,

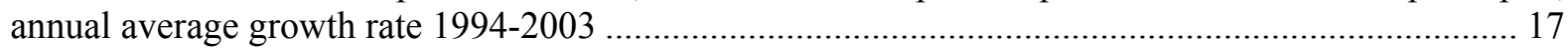

Figure 9. Gaps relative to the United States in GDP per capita and per hour worked, and in labour

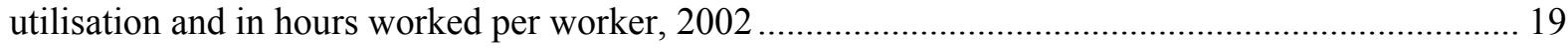

Figure 10. Levels of GDP per capita with different adjustments for leisure time of workers relative to the United States in 2001

Figure 11. Real annual change of per capita household disposable income and adjustments for changes in

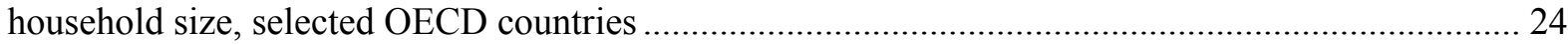

Figure 12. Levels of "equally-distributed" household disposable income for different values of the

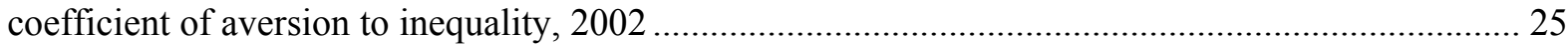

Figure 13. Cross-country correlations between per capita GDP and different social indicators in OECD countries

Figure 14. Median value and confidence interval of a composite index based on selected social indicators

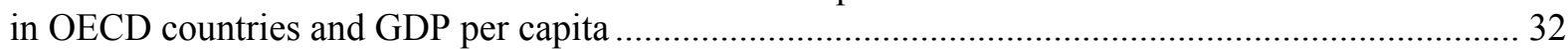

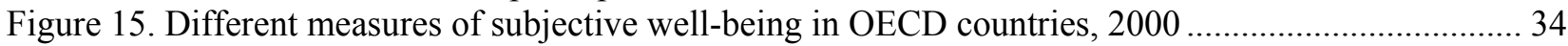

Figure 16. Cross-country relation between average life-satisfaction and GDP per capita in OECD countries,

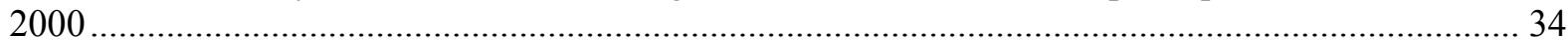

Figure A.1. Synthetic indexes of social conditions and GDP per capita, most recent year........................ 54

Figure A.2. Median value and confidence interval of composite indexes for four categories of social indicators in OECD countries and GDP per capita. 


\section{EXECUTIVE SUMMARY}

1. All discussions about the desirability of policy reforms rest on judgements about their effects on individuals and societal well-being. Yet, suitable measures for assessing how well-being is changing over time or compares across countries are lacking. This problem is, of course, not new and standard economic theory has provided, over the years, a range of insights about the criteria and domains that are most critical for the measurement of well-being, and on the relation between well-being and measures of economic resources. This paper does not revisit this theoretical discussion, nor does it provide a comprehensive review of different approaches to the measurement of well-being. It rather assesses whether GDP per capita is an adequate proxy as a measure of well-being or whether other indicators - used either as substitutes or as complements to GDP per capita - are more suitable for that purpose. Attention is limited to only some of the factors that influence well-being, and excludes some critical elements such as the environment, home production and other non-market factors.

2. The main findings of the paper are the following:

- Within the national accounts framework, other - and possibly better - measures of economic resources than GDP per capita exist (e.g. net national product, net income) but data availability and reliability restrict the scope for cross-country and inter-temporal comparisons. The different economy-wide measures that are available are closely correlated with each other, and paint a similar picture of the ranking of countries and developments over time, while there are larger differences when comparing income measures for the economy as a whole and for households.

- Illustrative calculations to "extend" measures of economic resources to include leisure time, the sharing of income within households and distributional concerns suggest that cross-country ranking based on the augmented indicators and on GDP per capita are generally similar, although they have evolved differently over time.

- Several indicators exist to measure specific social conditions that are related to well-being. Across OECD countries, levels of most of these social indicators are significantly correlated to GDP per capita while changes over time are not. A composite index based on these indicators points to significant difference in performance relative to GDP per capita in around half of countries, whatever the weights used.

- Survey-based data on happiness and life-satisfaction across OECD countries are only weakly related to levels of GDP per capita. Research on these subjective measures suggests that there are several distinct domains - such as joblessness, family and community ties - that contribute to overall life-satisfaction and that their influence cannot be reduced to a single dimension of economic resources.

3. In summary, measures of economic growth remain critical for any assessment of well-being but they need to be complemented with measures of other dimensions of well-being. How best to integrate these different measures is an open question. One approach is to take measures of economic resources as a starting point and then introduce a series of corrections to incorporate other arguments, but internationallyagreed standards on how to value these various non-market factors have yet to be developed. A different approach is to use various non-monetary indicators alongside conventional measures of economic resources: while still lacking a coherent conceptual and statistical framework, these indicators provide information that is relevant for the assessment of well-being. 


\section{RESUMÉ}

4. Tous les débats sur l'opportunité des réformes reposent sur des considérations relatives à leurs impacts sur le bien-être des individus et de la société. Pour autant, des mesures appropriées font défaut pour mesurer l'évolution du bien-être au fil du temps ou effectuer des comparaisons entre pays. Ce problème n'est, bien sûr, pas nouveau et la théorie économique fourni un éventail d'idées sur les critères et les domaines qui sont les plus importants pour mesurer le bien-être, ainsi que sur la relation entre le bienêtre et les mesures des ressources économiques. Ce document ne revient pas sur ce débat théorique et n'apporte pas non plus un examen exhaustif des différentes approches sur les mesures du bien-être. Son objectif, plus limité, est celui d'évaluer si le PIB par habitant peut être considéré comme une mesure adéquate du bien-être ou si d'autres indicateurs - utilisés comme substituts ou comme compléments au PIB par habitant - seraient plus appropriés. Seuls quelques-uns des éléments qui influent sur le bien-être seront examinés dans cette étude, tandis que d'autres facteurs importants tels que l'environnement, la production domestique et les autres productions non marchandes seront laissés de coté.

5. Les principaux enseignements sont les suivants :

- Dans le cadre des comptes nationaux, il existe d'autres mesures des ressources économiques qui pourraient être plus satisfaisantes - que le PIB par habitant (par exemple, le produit national net et le revenu net), mais les problèmes de disponibilité et de fiabilité des données limitent les possibilités de comparaison entre les pays et d'une période à l'autre. Les différents indicateurs macroéconomiques disponibles sont étroitement corrélés et donnent une image similaire du classement des pays et de l'évolution dans le temps, alors que les différences sont plus marquées lorsqu'on compare les indicateurs de revenu pour l'économie dans son ensemble et pour les ménages.

- $\mathrm{Si}$, à titre illustratif, on "élargit" les mesures des ressources économiques de façon à prendre en compte le temps de loisir, le partage des revenus dans la catégorie des ménages et les aspects distributifs, on constate que le classement des pays sur la base des indicateurs élargis et celui sur la base du PIB par habitant sont généralement similaires, même s'ils ont évolué différemment dans le temps.

- Il existe plusieurs indicateurs pour mesurer certains résultats sociaux liés au bien-être. Pour les pays de l'OCDE, le niveau de la plupart de ces indicateurs sociaux est corrélé de façon significative au PIB par habitant, ce qui n'est pas le cas si l'on considère l'évolution dans le temps. Un indice composite reposant sur ces indicateurs fait apparaître des différences significatives de performance par rapport au PIB par habitant dans la moitié environ des pays, quelles que soient les pondérations utilisées.

- Les données d'enquêtes sur le bonheur et la satisfaction de la vie réalisées dans les pays de l'OCDE ne sont que faiblement reliées au niveau de PIB par habitant. Les recherches consacrées à ces indicateurs subjectifs montrent que plusieurs éléments spécifiques - notamment le nonemploi, la famille et les liens communautaires - contribuent à la satisfaction globale de la vie et que leur influence ne peut être ramenée à la seule dimension des ressources économiques. 
6. En résumé, les mesures de la croissance économique restent cruciales pour toute évaluation du bien-être, mais il faut les compléter par des mesures des autres dimensions du bien-être. Il reste à savoir comment intégrer de façon optimale ces différentes mesures. Une solution consiste à prendre comme point de départ les mesures des ressources économiques, puis à introduire une série de correctifs pour tenir compte d'autres aspects, mais on ne dispose pas encore de normes internationales pour évaluer ces divers facteurs non marchands. Une autre solution est d'utiliser différents indicateurs non monétaires en complément des mesures des ressources économiques. Même si un cadre conceptuel et statistique cohérent leur fait encore défaut, ces indicateurs fournissent des informations pertinentes pour l'évaluation du bienêtre. 


\section{INTRODUCTION}

7. The OECD Going for Growth publication focuses on policies that have the potential to improve economic performance as measured by GDP per capita. However, the well-being of individuals and households does not only depend on GDP per capita, but also on other factors, such as leisure time, environmental quality, increases in competences and longevity, and distributive issues.

8. This paper reviews different measures of well-being and how they relate to levels, rates of change and international rankings of GDP per capita. Box 1 provides some relevant elements from the economic literature on the theoretical discussion of well-being. Section 2 describes alternative measures of economic resources that can be compiled based on national accounts, both for an economy as a whole and limited to the household sector. Section 3 presents illustrative calculations on the inclusion of different factors leisure time, living arrangements and income inequality — that may influence well-being. Section 4 presents evidence on how a range of non-monetary indicators of social conditions relate to per capita GDP and how they might be aggregated into a composite index. Finally, Section 5 discusses evidence and interpretation from survey-based measures of happiness and life-satisfaction. Supporting material is provided in the Annex.

\section{Box 1. Some insights on well-being provided by the economic literature}

Economic literature argues that individuals derive well-being from the satisfaction of their wants according to their own preferences. In practice, as the degree of satisfaction of individual's preferences cannot be observed directly, assessments of well-being need to rely on proxies. The one most commonly used is real income: for individuals, real income constrains their consumption possibilities while, for nations, production of both consumer and investment goods contributes to individuals' well-being today and in the future. Valuing quantities through market prices assures that, in equilibrium, these prices are representative of the marginal contributions of the different goods consumed to the utility of individuals. However real income is only a proxy of well-being:

- Income, as conventionally measured, departs from its theoretical definition (e.g. it excludes changes in asset values that influence what individuals can consume) and is more a measure of what society produces than of its consumption possibilities.

- Because it excludes a range of non-market items that influence well-being, income only measures the contribution to well-being of a specific set of economic activities. While practical concerns (often driven by the difficulty in measuring various items) guide decisions on what is included and what is excluded from measures of real income, these decisions have an impact on the assessment of well-being (Hicks, 1940).

- Market prices will not reflect the marginal contribution of various items to well-being when externalities or other distortions are present. Also, real income comparisons do not assure respect of individuals' preferences when these are not shaped as assumed by theory and when prices change over time.

- In theory, assessments of well-being are based on whether a person with given preferences would prefer one alternative to another. In practice, comparisons are done across space and time: when preferences differ across individuals, countries and time, differences in income do not necessarily translate into differences in well-being (Sen, 1979).

- Income comparisons across countries implicitly assume that nations consist of identical individuals, each consuming the same goods and sharing the same characteristics. In more general circumstances, however, well-being depends on both the level of income and its distributions. As, under a plausible set of assumptions, "social" orderings of various states cannot be based exclusively on individuals' preferences (Arrow, 1951) distributional judgments need to choose between alternative philosophies of social justice. 


\section{MONETARY MEASURES OF ECONOMIC RESOURCES}

9. Gross Domestic Product is designed to measure the value of production of those activities that fall within the boundary of the national accounts system. GDP estimates are subject to uncertainties and to difficult measurement problems in some areas (such as those in measuring production by the government sector, Box 2). Over and above these technical problems, however, is the question as to whether, of all the data that can be extracted from the System of National Accounts, GDP is best suited to the task of measuring the total value of the economic resources that affect well-being. This section examines alternative national-accounts-based measures of economic resources, notably national income and household consumption, and assesses if they paint a different picture of the evolution and cross-country comparison than that based on GDP.

\section{Box 2. The measurement of government production in national accounts}

The measurement of government output is particularly challenging, and this has implications for measuring overall GDP and the extent to which it can be used as a proxy for well-being. Measurement of government output is difficult because public services are often provided to direct users for free, or at a subsidised price, and thus cannot be valued using prices that reflect the marginal benefit to the consumer, as is the case, in principle, for market prices. As a result, the evaluation of public services output at current prices is based on the value of inputs, i.e. equating government output to the total cost of production. As regards volume measures, the most common estimation method up to now has been based on the extrapolation of base year-value of output by changes in the value of deflated inputs, thus implicitly assuming zero productivity growth. ${ }^{1}$

In recent years some OECD countries have started to measure changes in government production based on direct measures of output. For example, the United Kingdom has moved since 1998 to a direct (output-based) measure of changes in government production for around two-thirds of government final consumption. This has had implications for the measured growth of the UK economy. Between 1995 and 2003 GDP in constant prices grew by $23 / 4$ per cent per year using the direct output measure; if output in the public sector had continued to be measured by inputs, the corresponding growth rate would have been $3 \%$ per year (Atkinson, 2005). The implications for crosscountry comparisons of performance can be large (e.g. methodological differences in accounting for government output explain nearly half of the difference between the published growth rates in GDP of the United Kingdom and the United States between 1995 and 2003).

1. A few countries (e.g. Germany) assume positive productivity growth in the government sector extrapolated from relevant activities in the private sector.

\subsection{Measures of the economic resources of nations}

10. By construction GDP at factor cost is equal to gross income earned in the process of producing output. To measure the contribution that economic activities provide to the well-being of the residents of a country, income transfers received by residents from abroad should be added to GDP (and transfers made by residents to people in other countries should be subtracted) to arrive at a measure of Gross National Income (GNI). A second adjustment, to reflect the consumption of capital, is required to get a better measure of the economic resources that are available to individuals in a country for current and future consumption, resulting in a measure of Net National Income (NNI). This section examines whether use of GNI and NNI might give a different picture about trends and levels of the economic resources of a country than those based on GDP. 


\subsubsection{Gross national income: adjusting for net transfers from abroad}

11. In most OECD countries, the difference between GDP and GNI per capita is small since gross income inflows from abroad tend to be offset by gross outflows (Figure 1), resulting in an almost identical international ranking based on purchasing power parities (Annex, Section 3). However, the distinction between national and domestic income matters for a few countries. This is notably the case for Ireland where GDP per capita has risen substantially in the past two decades to one of the highest levels in the OECD area but where GNI per capita is still only around the average level in the OECD countries. Similarly, in Luxembourg, GNI per capita is about $13 \%$ below the level of GDP per capita. GNI per capita is also somewhat lower than GDP per capita in New Zealand, Australia, the Czech Republic and Hungary. By contrast, in Switzerland, United Kingdom and Belgium, positive inflows of capital income from abroad result in a higher level of GNI than GDP per capita.

Figure 1. GDP and GNI per capita 2003, US\$ current prices and current PPPs

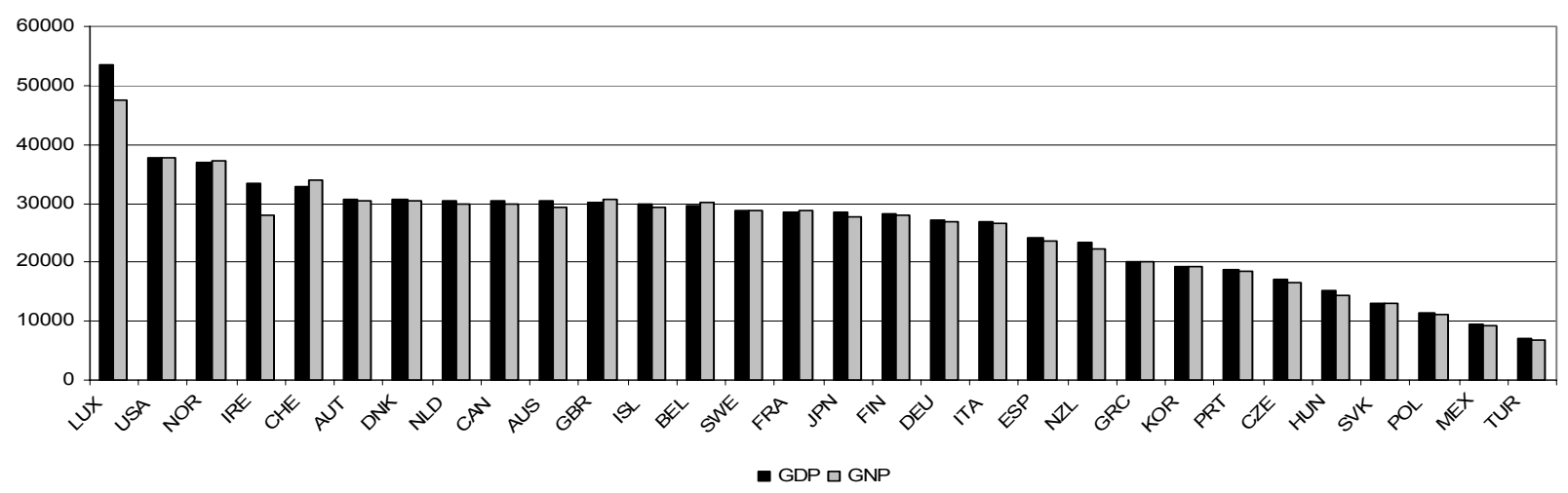

Source: OECD Annual National Accounts.

12. Apart from different movements in net transfers from abroad, the evolution of GNI and GDP in volume can differ due to "terms-of-trade" effects. The terms-of-trade effect arises because real GNI is obtained by deflation with the price index for domestic final demand rather than the price index for GDP. It measures the rate at which exports can be traded against imports from the rest of the world. Thus, a termsof-trade improvement makes it possible for an increased volume of goods and services produced abroad to be purchased by residents out of the incomes generated by a given level of domestic production. This price effect measures the change in "purchasing power" relative to a specific reference year, and thus varies with respect to the choice of reference year.

13. Looking at trend growth of real GDP and real GNI per capita over the past ten years shows that differences between the two measures are relatively small, on average only 0.1 percentage point (Figure 2). ${ }^{1}$ However, in Korea and Ireland, real GDP per capita grew substantially faster, around one percentage point, than real GNI per capita. Both countries suffered relatively large terms-of-trade losses and they are also large ICT producing countries for which the export prices of their goods have fallen recently. In contrast, in Denmark, New Zealand, Australia and United Kingdom, GDP grew about 0.5 percentage points slower than GNI. These differences in growth rates were due, in half the cases, to termsof-trade effects and, in the other half, to movements in net income transfers.

1. Trend growth refers to the average annual growth rate over the period 1994-2003. 
Figure 2. Average annual growth in real GDP and real GNI per capita, 1994-2003

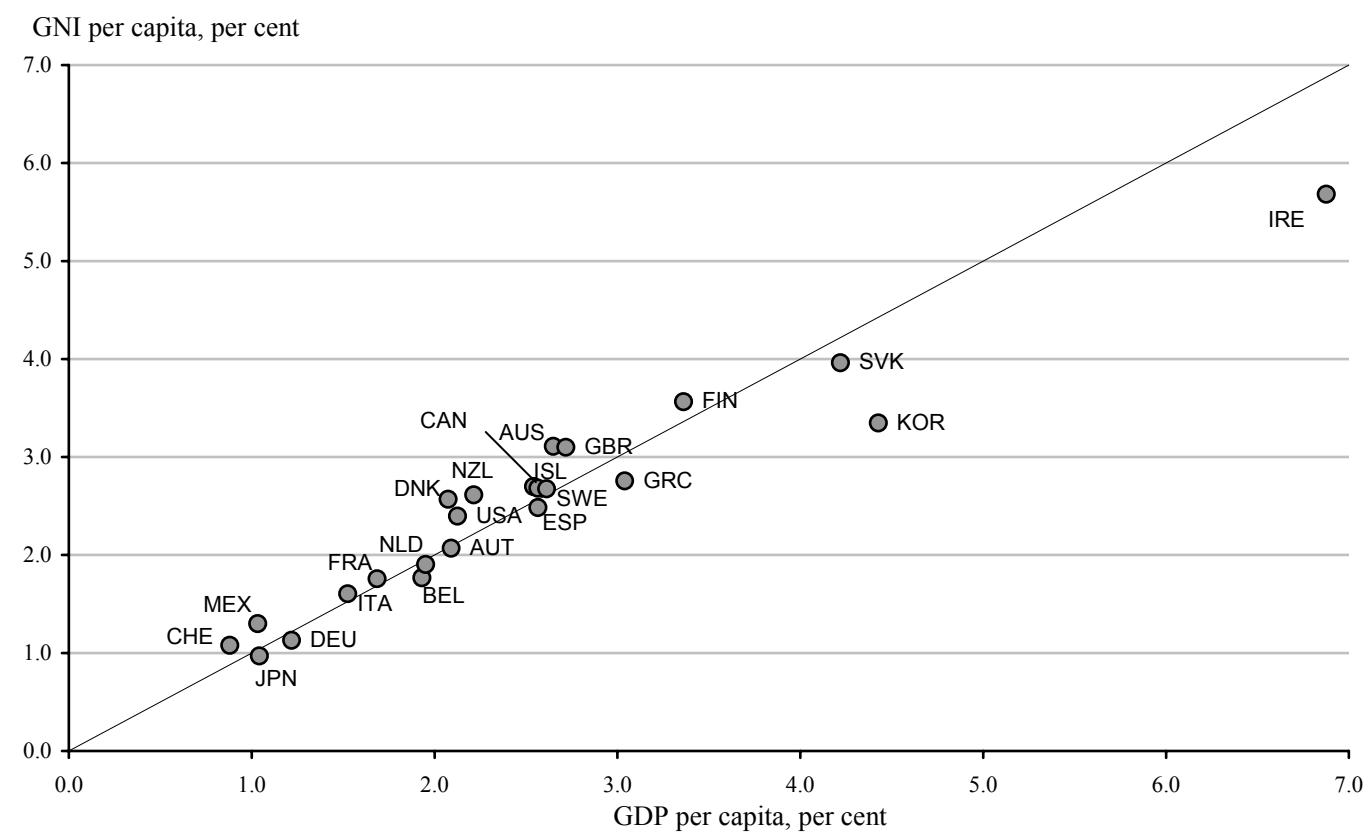

Source: OECD Annual National Accounts.

\subsubsection{Net national product and the importance of capital consumption}

14. Net domestic product (NDP) is the maximum amount of output that can be spent on consumption during a year while maintaining the country's future productive capacity unaltered. Consumption of capital is in most countries estimated using essentially the same method (perpetual inventory method and assumed depreciation patterns). A few countries use other methods to estimate capital stocks and depreciation. The use of different methods and/or parameters across countries reduces the international comparability of estimates of net domestic product.

15. Taking official statistics at face value, the ranking of countries on the basis of NDP per capita is almost identical to that based on GDP per capita (Figure 3). Thus, the level of NDP per capita is on average in OECD countries about $85 \%$ of the level of GDP per capita, with little variation in this share across countries. Nonetheless, in Japan, the Czech Republic and the Slovak Republic, consumption of capital is relatively large in relation to GDP and the level of NDP is around $80 \%$ of that of GDP per capita. By contrast, in Greece, Mexico, United Kingdom, United States and Ireland, NDP per capita is around $90 \%$ of the level of GDP per capita. 
Figure 3. GDP and NDP per capita, 2003, US\$ current prices and current PPPs

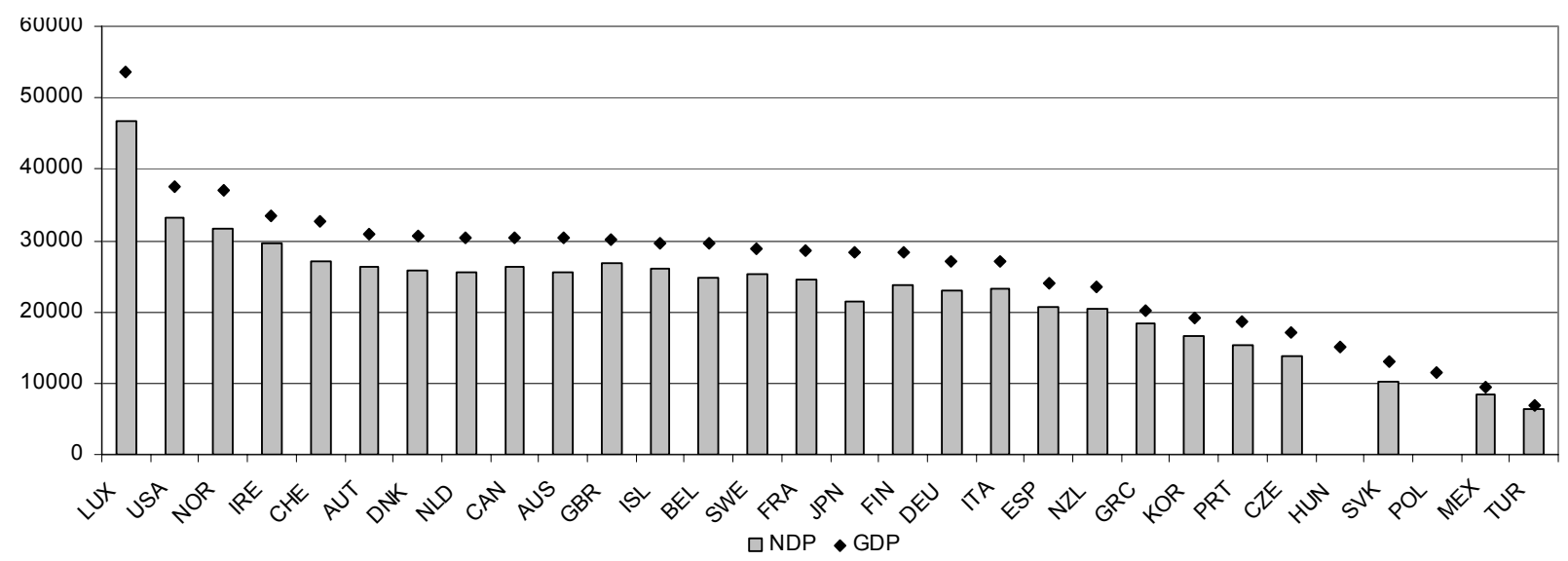

Source: OECD Annual National Accounts.

16. Capital consumption has grown somewhat faster than real GDP in the past decade in most OECD countries. This reflects growing investment in new technologies with shorter service lives. As a result, growth in real NDP per capita was on average 0.1 percentage points lower than that of real GDP per capita in OECD countries for which data on capital consumption are available (Figure 4). This gap was significantly larger in Denmark, Switzerland and United States, while in Austria, Iceland and Sweden, NDP growth was broadly in line with GDP growth. In contrast, in Finland, Slovak Republic and United Kingdom, NDP growth exceeded that of GDP.

Figure 4. Average annual growth in real GDP and real NDP per capita, 1994-2003

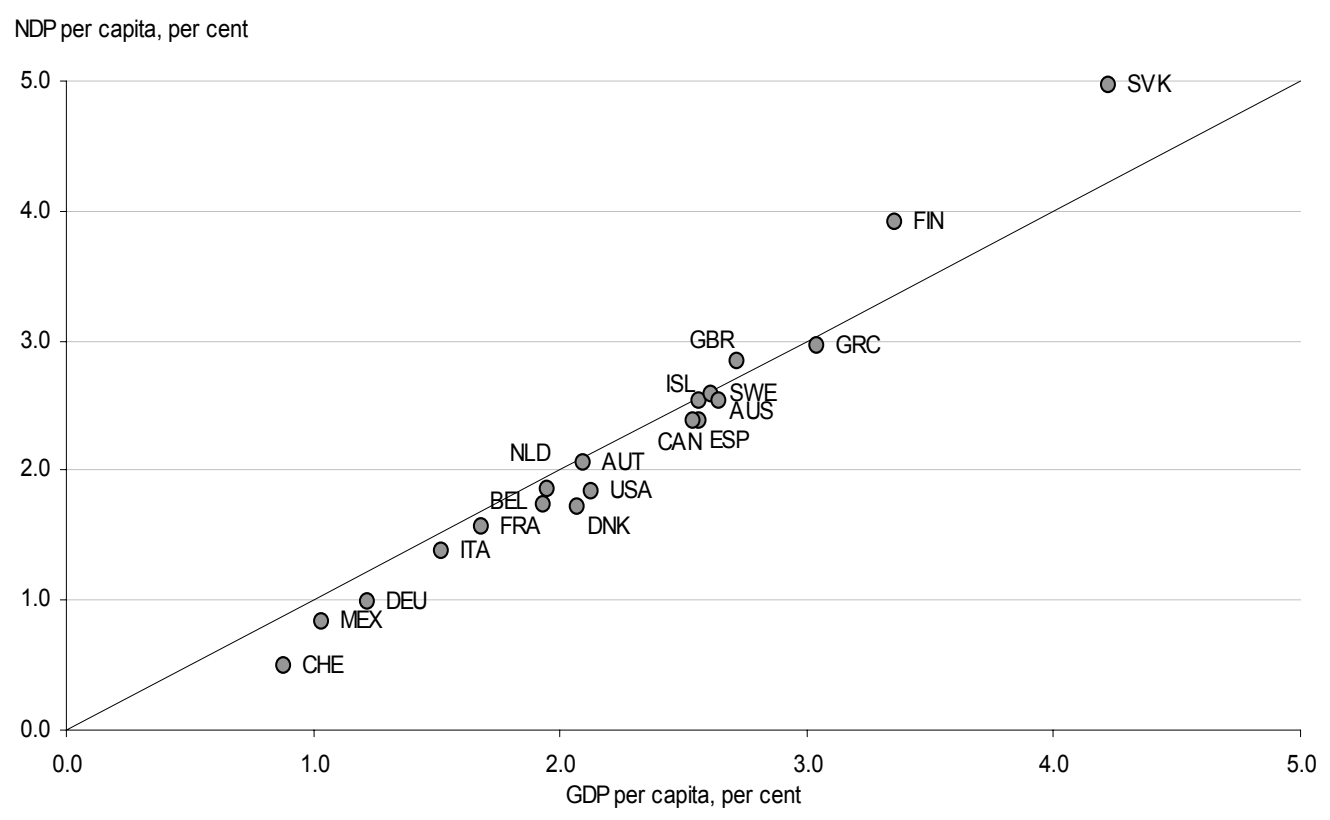

Source: OECD Annual National Accounts. 


\subsubsection{Net national income: adjusting for net transfers from abroad and capital depreciation}

17. Taking the impact of net transfer income from abroad and consumption of capital together shows that the levels of net national income (NNI) per capita are systematically below levels of GDP per capita, indicating that the latter overstate the level of economic resources that contribute to well-being. However, the ranking of countries on the basis of NNI per capita is similar to that based on GDP per capita (Figure 5), with simple and rank correlation coefficients of 0.98 and 0.95 , respectively. While this indicates that GDP per capita ranking is a useful proxy of relative income per capita levels across countries, the difference is significant for a few countries, notably Ireland, the United Kingdom and Iceland. The growth rate of real GDP and real NNI per capita is generally similar in most countries (simple and rank correlation coefficients of 0.96), again indicating that the growth in real GDP per capita can be a useful proxy for growth in real income per capita (Figure 6).

Figure 5. GDP and NNI per capita, in US\$ current prices and PPPs, 2003

Ranked in descending order by GDP per capita

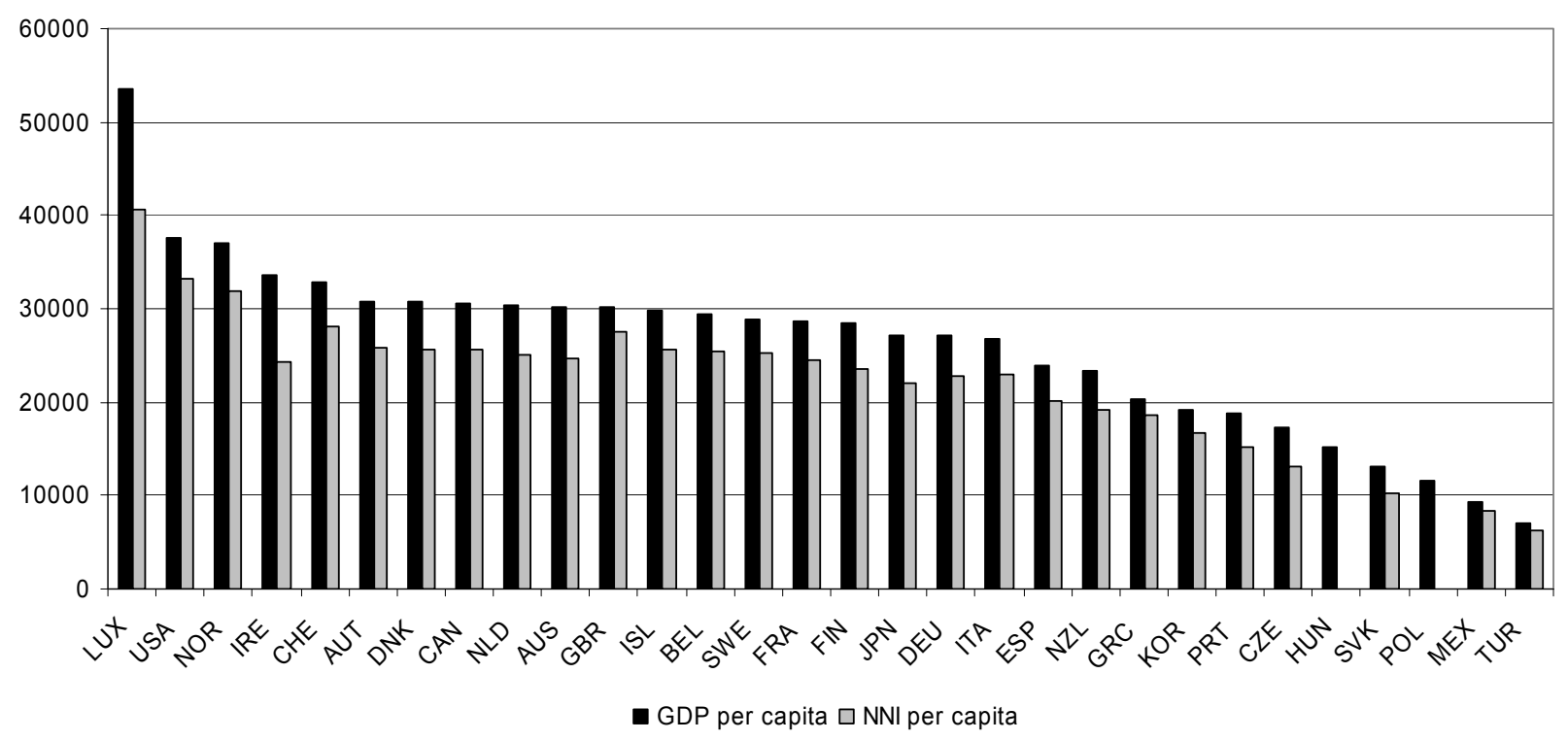

Source: OECD Annual National Accounts. 
Figure 6. GDP and NNI per capita growth, average annual growth, 1994-2003

Percent

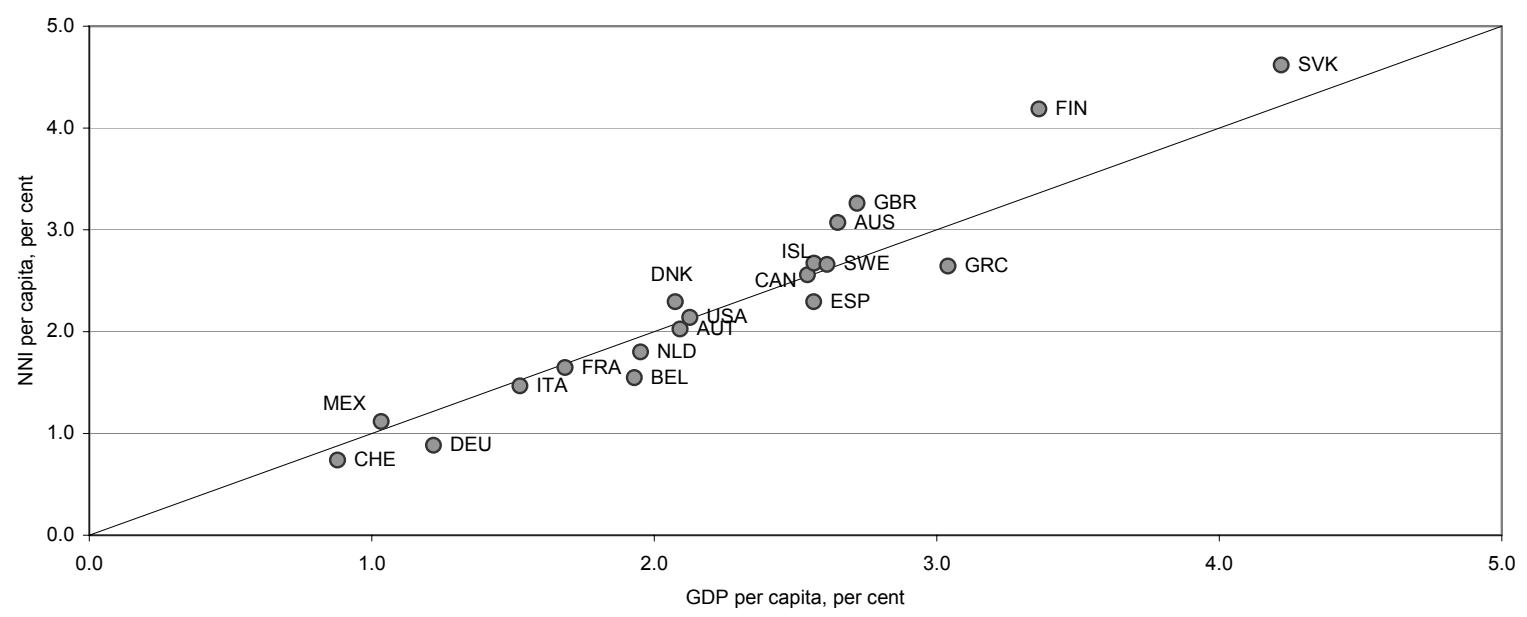

Source: OECD Annual National Accounts.

\subsection{Measures of the economic resources of households}

18. The well-being of individuals can be linked to their current and future consumption of economic resources rather than to economy-wide measures of production or income. Within the national accounts, three measures can be used to provide estimates of the consumption possibilities of individuals (although income and consumption measures in national accounts do not correspond closely to theoretical definitions). The first is households' disposable income per capita, which provide a measure of both current consumption spending and of future consumption that could be financed by current saving. The second measure is final consumption expenditure of households per capita. The third measure refers to "actual" household consumption per capita which, as defined in national accounts, includes an estimate of government and non-profit institutions (NPI) services (such as education and health) provided to households for free at point of delivery (or at subsidies prices). ${ }^{2}$ All of these measures may be compared across countries through the use of purchasing power parities for private consumption. ${ }^{3}$

19. As might be expected, all three household measures of resources per person are significantly lower than GDP per capita (Figure 7). Thus, household disposable income, private consumption and "actual" consumption per person are 42, 47 and 30\% lower than GDP per capita on average in the OECD countries respectively. There is wide variation in the gap between the different household measures and GDP per capita. For example, the gap between disposable income and GDP per capita ranges from $20 \%$ in

2. While this section presents evidence about the impact of in-kind services provided by governments and not-profit institutions on household final consumption expenditure, the same adjustment can applied to household disposable income.

3. Thus the differences between measures of economic resources for households and measures for the economy as a whole also reflect differences between purchasing power parities for GDP and for private consumption. Because of the low prices of consumption goods relative to other prices in the United States, purchasing power parities for private consumption are higher than those for GDP in all OECD countries except Luxembourg; the gap between the two indices is $9 \%$ or more in Finland, Iceland, Japan, Korea, Norway, Poland, the Slovak Republic and Turkey. 
Turkey to $57 \%$ in Denmark. However, notwithstanding these level differences between the different measures, there is a strong correlation between levels of household income/consumption and GDP per capita (rank correlations above 0.83 and simple correlations above 0.90 ). The ranking of countries is also similar for all the indicators.

Figure 7. Consumption, actual consumption and GDP per capita, 2003

US\$ current prices and PPPs for GDP and consumption

Sorted in descending order of GDP per capita

$\square$ Final consumption $\quad \square$ Government and NPI services $\quad \square$ Disposable income • GDP

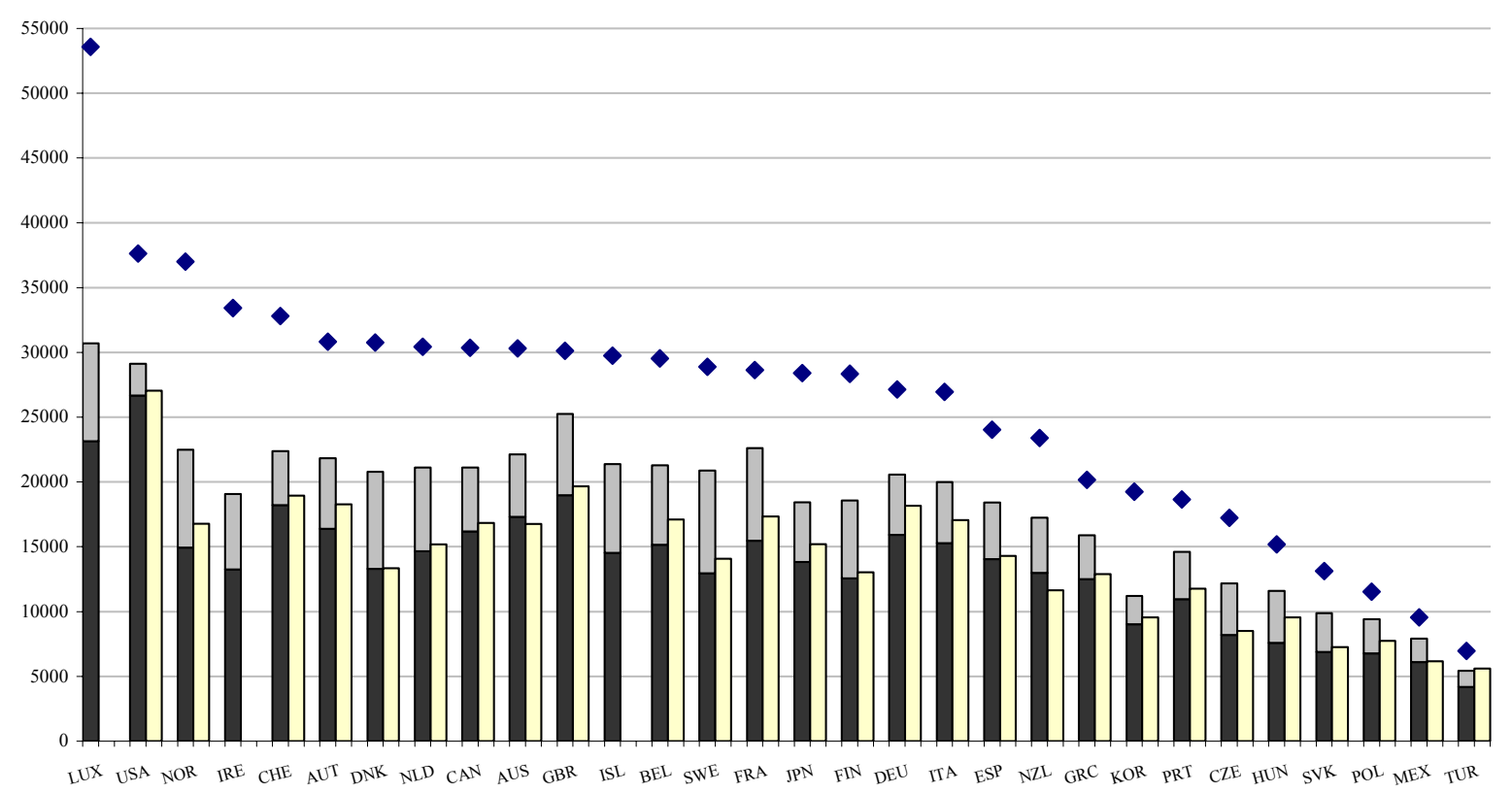

Source: OECD Annual National Accounts and OECD Economic Outlook No. 76.

20. The differences are starker when looking at the growth rates of real GDP per capita and of measures of the economic resources of households. Over the 1994-2003 period household real disposable income per capita increased at a lower rate than real GDP per capita in most OECD countries except Norway, Hungary, France and the Czech Republic. The gap between the annual growth rate of real GDP and of real household disposable income per capita was especially large in Korea, and exceeded one percentage point in Belgium, Canada, Finland, Italy, Slovak Republic and Sweden. Final consumption expenditure per capita also grew slower than GDP per capita, increasing on average by $2.3 \%$ per year compared with an average growth in GDP per capita of $2.6 \%$ (Figure 8 ). The increase in final consumption expenditure per capita fell short of GDP per capita growth by more than one percentage point in Luxembourg and Ireland, while it was well above real GDP per capita growth in the Norway and Hungary. 
Figure 8. Real household's disposable income, real final consumption expenditure and real GDP per capita, annual average growth rate 1994-2003

\section{Per cent}

GDP and household disposable income per capita

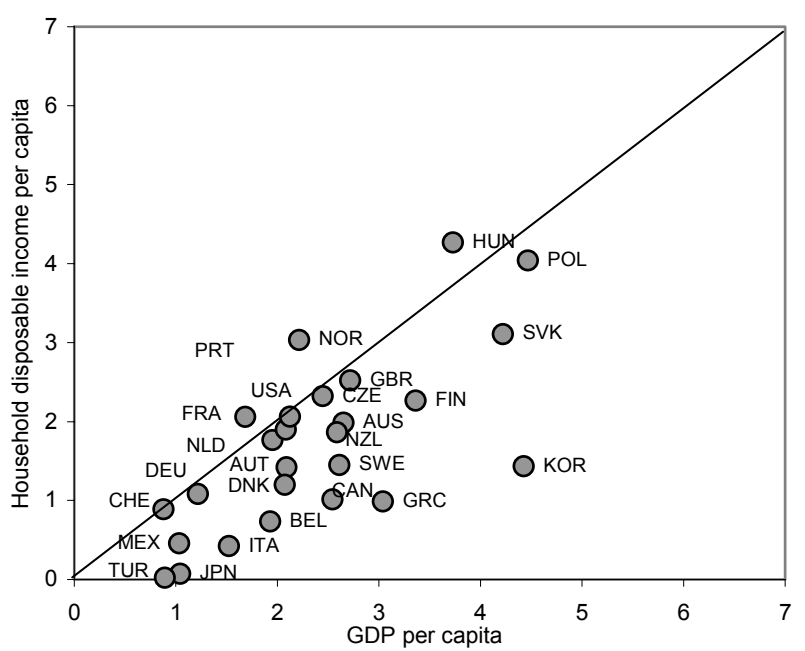

GDP and final consumption expenditure per capita

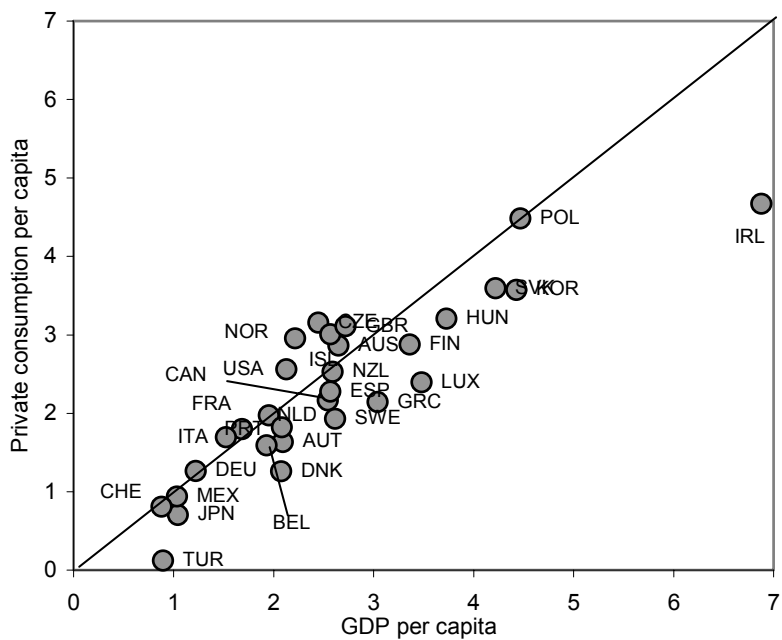

Source: OECD Annual National Accounts and Economic Outlook No. 76.

\subsection{Summing up}

21. There is altogether a fair degree of convergence in growth rates of the different measures of economic resources for the economy as a whole. But there is less convergence between growth rates of resources for the economy as a whole, on the one hand, and growth rates of resources for the household sector, on the other. Thus, an assessment of cross-country developments of economic resources will depend on the measure being used for the comparison. Looking at levels of economic resources there is not much difference in the ranking across countries based on various measures for the economy as a whole, but the difference is somewhat larger between GDP per capita and household measures. Overall, in comparing levels and growth rates of economic resources between countries, GDP per capita can be employed, though it should be kept in mind that it may not be closely aligned in all countries with household resources, which are by construct less encompassing measures. 


\section{THE INFLUENCE OF OTHER FACTORS ON WELL-BEING}

22. The determinants of individual and societal well-being go beyond production and consumption of economic resources. Several approaches have been explored to "extend" national accounts aggregates to a range of dimensions that have value for individuals and communities. ${ }^{4}$ These approaches - that require attaching a monetary value to activities that are not traded in markets and to factors that are not usually brought into relation with the measuring rod of money - raise however several controversial issues (Box 3). This section presents some illustrative calculations of the importance of some of these dimensions: leisure time, household size and inequality.

\section{Box 3. Monetary valuation of non-market factors}

Monetary valuation of non-market factors that influence individuals' well-being requires some problematic assumptions. The main difficulty is how to estimate the prices to be applied to quantities of various non-market activities. In principle, imputed prices should reflect the relative importance of different activities for individuals' wellbeing, as in the case of the national accounts. However, in most cases imputation cannot be based on revealed preferences, because of the absence of market transactions. To overcome this difficulty estimates have to rely on imputations of the shadow price of these activities. Non-market activities include both personal activities and unrecorded economic activities. The former are activities that cannot be delegated to a third person, such as leisure and recreational activities; the latter include home production and those activities that, while contributing to individuals' well-being, are not recorded in the national accounts. Problems in valuing such activities include:

- Fist, valuation of unrecorded economic activities can be based either on the values of inputs or on that of outputs. While the second method is, in theory, preferable for measuring the benefits occurring to individuals, data availability often constrains the estimation to the inputs side. ${ }^{1}$

- Second, valuation of inputs can be based either on replacement costs (i.e. the money that should be paid to a third person performing the same activity) or opportunity costs (i.e. the foregone earnings of the person who perform this non-market activity); while the two methods should provide in theory the same estimation, in practice they lead to different results. ${ }^{2}$

- Third, valuation based on opportunity costs is the only option in the case of personal activities. However, even in this case, several alternatives exist (i.e. opportunity cost for each individual or based on "averages"). In the case of leisure, these alternatives give very different results.

- Last, non-market activities can be priced at either their marginal or total value. Total values provide information on the willingness to pay for infra-marginal units, but require comprehensive surveys.

1. In both cases, the general procedure consists in assigning to non-market activities the value of a comparable market-activity, whenever this exists. When equivalent market activities do not exist, estimates generally rely on the value of the expected benefits associated to these activities.

2. In theory, replacement costs (adjusted for productivity in executing the activity) and opportunity costs (corrected for the utility or disutility associated to one's own performance in the activity) are equal when individuals optimise their allocation of time. In practice, differences arise due to transaction costs, imperfect flexibility in the allocation of one's own time and rigidity in labour supply.

4. One approach values items that are omitted in conventional measures of income at market prices. A second approach relies on "equivalent income" that reflect the willingness-to-pay of each individual for additional factors of well-being. An early formulation of the notion of "equivalent income" is provided by Samuelson (1974), i.e. the income that would give each individual his current level of utility if the prevailing prices were at some reference level. A more recent extension is provided by Fleurbaey (2003), who defines "equivalent" income as the amount that would give each individual his current utility if other non-market features were at some reference level. While this approach has the advantage of providing income measures that are comparable across individuals and that respect their preferences, it requires data on individuals' willingness-to-pay that are rarely available. 


\section{1. $\quad$ Accounting for leisure time}

23. Conventional SNA-based measures of economic activity do not attach any value to leisure. However, the leisure time enjoyed by individuals is obviously important for any evaluation of well-being, and workers' choices on how to allocate their time have a direct bearing on cross-country comparisons of economic aggregates. For most OECD countries, the gap in GDP per capita relative to the United States is due to relatively low levels of labour utilisation (total hours worked per person, Figure 9). ${ }^{5}$ These differences in labour utilisation reflect both large variations in employment rates across countries — with institutional and policy factors explaining a large part of these differences ${ }^{6}-$ and, in some countries, differences in annual hours worked per worker.

Figure 9. Gaps relative to the United States in GDP per capita and per hour worked, and in labour utilisation and in hours worked per worker, 2002

Countries are ranked in ascending order of their gap in GDP per capita
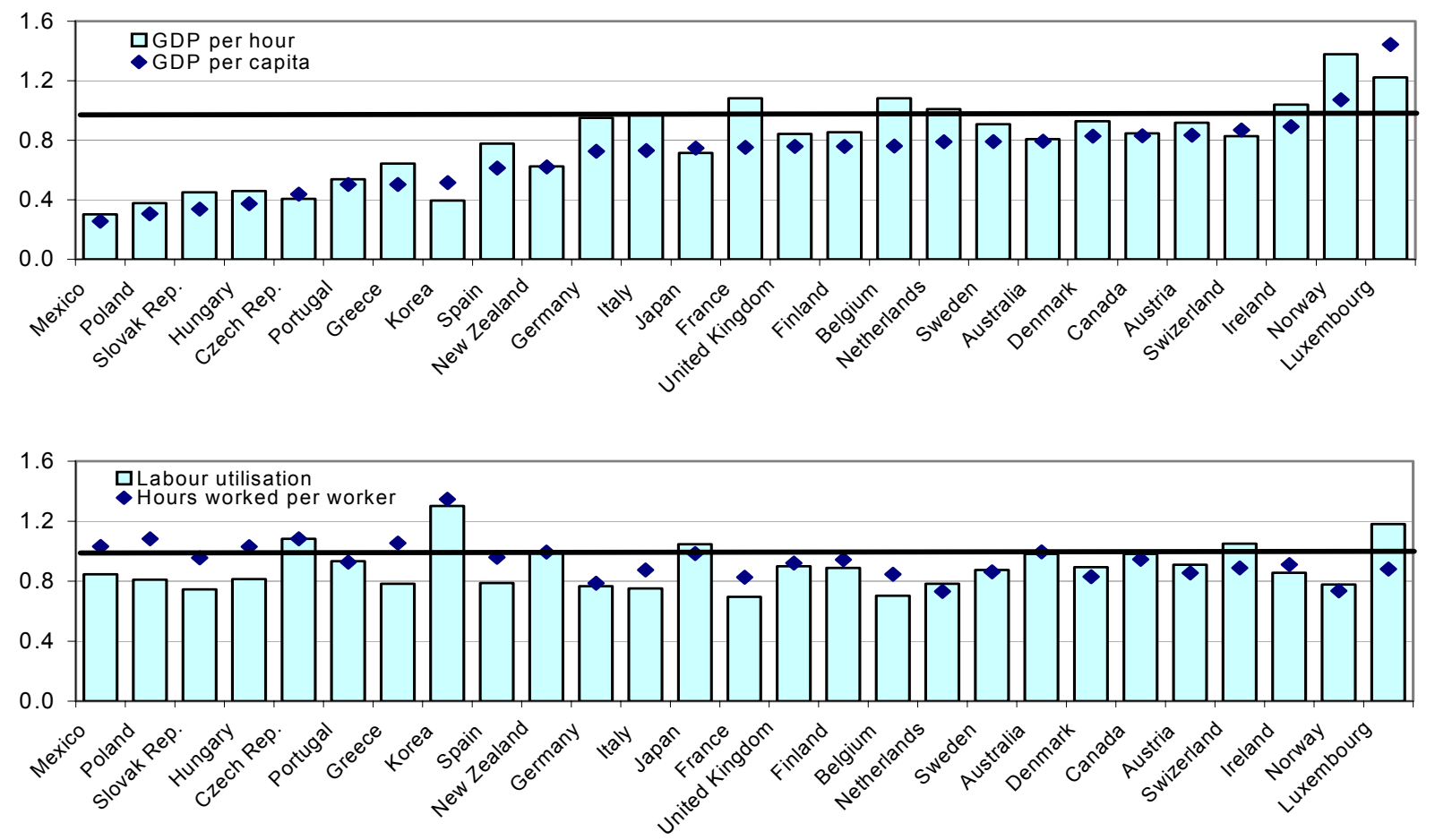

Source: OECD Productivity database.

24. Cross-country differences in average hours worked per worker suggest that taking leisure into account could lead to a different assessment of the level and growth rates of well-being from that based on national accounts. However, because of a range of methodological problems on how to measure the price and quantity of leisure (for example, whether the "productivity" of leisure time should be assumed to have risen in line with technological progress and greater availability of consumer durables), there is no

5. Historical evidence reviewed by Gordon (2004) shows that average GDP per hour in 12 European countries fell from around $80 \%$ of the level prevailing in the United States in 1860 to less than $50 \%$ by 1950 , before recovering to $93 \%$ of US levels in 2000. In 2002, GDP per hour worked exceeds US levels in several OECD countries.

6. For example, OECD work on the determinants of labour force participation rates of older workers shows that, if European workers had the same incentives to retire as their US counterparts, this would lead to small difference in retirement behaviour on both sides of the Atlantic (Duval, 2004). 
accepted standard on how to account for leisure time within national accounts. Some illustrative calculations, based on specific assumptions, highlight the potential effects of leisure time on "leisure adjusted" GDP per capita, but also show that results critically depend on the assumptions made.

- Adding an estimate of the level of leisure time of workers to GDP per capita increases well-being in all countries, although by different amounts. ${ }^{7}$ Figure 10 plots gaps relative to the United States in "leisure-adjusted" GDP per capita in 2001, using three assumptions on valuation. As working hours in the United States are longer than in most other OECD countries, giving any positive value to leisure narrows gaps in "leisure-adjusted" GDP relative to those based on GDP per capita. Changes in the ranking of OECD countries are however small (the rank correlation is 0.97 when valuing leisure at half of hourly compensation, and 0.93 when valuing it at either GDP per capita or hourly compensation).

- Adding an estimate of the change in leisure time of workers to real GDP per capita also affects judgments on how well-being is changing over time (Annex Table A.6). When valuing leisure at hourly compensation, and not allowing for higher productivity of leisure time, the annual growth rate of "leisure-adjusted" GDP exceeds that of GDP per capita by around 0.1 percentage point on average, and by 0.2 percentage points or more in Denmark, France, the Netherlands and Portugal, where the reduction in working hours has been larger. When valuing leisure at GDP per hour, or at nominal wages but allowing for higher productivity of leisure, the difference in the annual growth rates of the two aggregates widens to 0.2 percentage points on average, and to 0.4 percentage points or more in some countries.

Figure 10. Levels of GDP per capita with different adjustments for leisure time of workers relative to the United States in 2001

Levels in current US \$ at PPPs rates

Sorted in ascending order of the gap in real GDP per capita

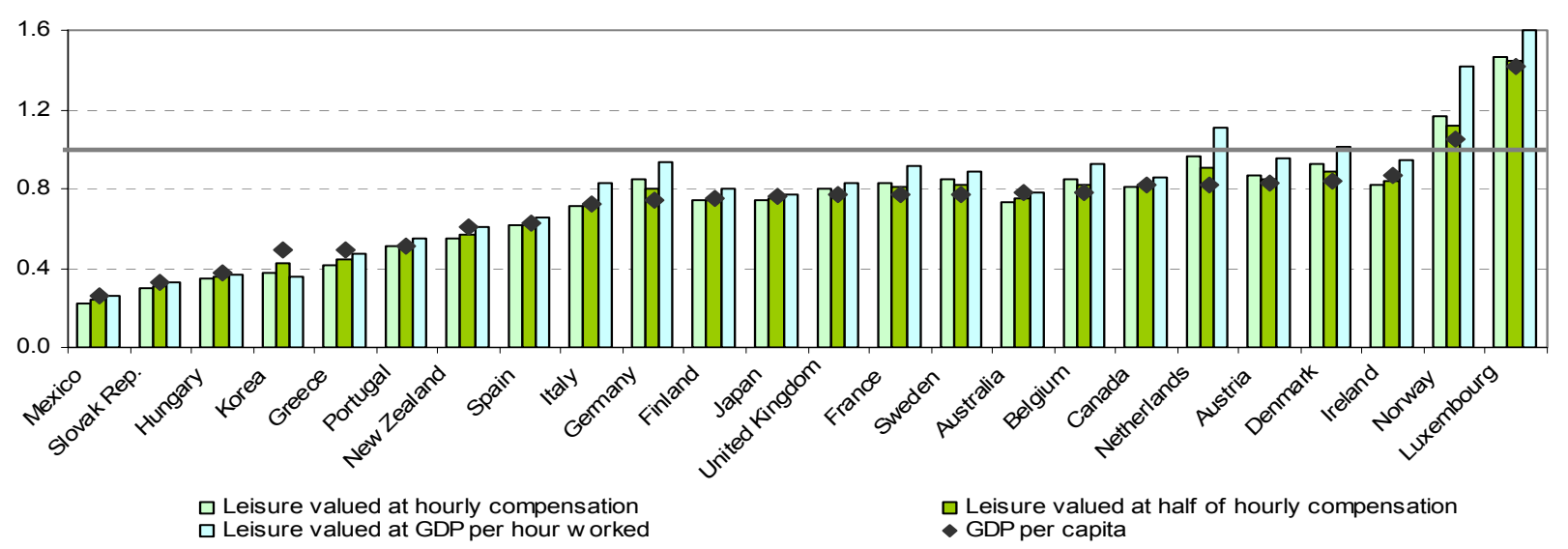

Note. The bolded (horizontal) line is the level of "leisure adjusted" GDP per capita in the United States. The quantity of leisure time of workers is estimated by deducting from the time-endowment of each worker a (common) estimate of the time devoted to personal care and unpaid activities and (country-specific) OECD estimates of annual working hour per worker. Leisure time is value using three different prices: hourly compensation of employees; half of hourly compensation; and GDP per hour worked. Further methodological details are given in the Annex, Section 4.

Source: OECD Productivity database and Annual National Accounts.

7. The estimates presented in Figure 10 do not consider the leisure time of people unemployed and out of the labour force, as this would require additional assumptions on the nature (voluntary or involuntary) of unemployment, and valuation of home production. Other methodological assumptions underlying the calculations shown in Figure 10 are described in the Annex, Section 4. 
25. Different valuation assumptions partly relate to the determinants of differences in leisure time across countries. One explanation for lower working hours in Europe relative to the United States is that it reflects the greater value attributed to leisure by Europeans. This is the explanation put forward by Blanchard (2004), who links these differences to long-term cultural factors. However, as European workers worked more than their US counterparts up to the late 1960s, it is difficult to invoke long-standing cultural differences to explain current labour-utilisation patterns. A different explanation focuses on the role of policies and institutions, which may both depress and boost working hours. On the one hand, Prescott (2004) argues that relatively low hours worked per person in Europe can be fully explained by policy distortions arising from high marginal taxes on labour. ${ }^{8}$ On the other hand, market failures (e.g. asymmetric information and inter-personal complementarities in the consumption of leisure) could boost hours worked in some countries beyond the social optimum (Alesina et al. 2005 and Landers et al., 1996).

\subsection{Household size and economies of scale in consumption}

26. Estimates of per capita household income in the national accounts are obtained by summing income across all households and dividing the total among the resident population. One limit of these data is that they do not reflect the pooling of resources that occurs within each household and differences in the income that households of different size will require for assuring the same well-being of their members. Further, when national accounts data for other institutional sectors are of better quality than those for households - as is often the case for several OECD countries - the national accounts measure of household income may be affected by statistical discrepancies between the different accounts. Surveybased measures of household income allow these limits to be addressed.

27. Adjusting income for household size is, however, not without problems.

- First, there is no consensus about the extent to which resources are shared within households, or on how needs change with household size. ${ }^{9}$ Comparative research on income distribution conventionally relies on values of the elasticity of household's needs with respect to household size that are common across countries: in reality, there are no a priori reasons for this elasticity to be the same across countries and to remain constant over time. Different choices of this elasticity will affect estimates of the levels of "equivalised" income (i.e. household income adjusted for household size), although they are less important for estimating changes over time. ${ }^{10}$

- Second, adjusting income for household size reflects the sharing of consumption goods. It does not allow a broader assessment of the consequences of living with others: a lower household size may well correspond to the preferences of many people who, as their income and health improve, can now afford to live alone.

8. Prescott examines the role of taxes, in particular marginal tax rate on labour income, in accounting for the differences in labour supply across G7 countries. He finds that high marginal taxes account for a predominance of the difference in a point of time as well as changes over time in labour supply, except in Italy. However, the result relies critically on assumptions that ensure a high elasticity of labour supply which do not square with micro estimates of this elasticity (Alesina et al., 2005).

9. Beyond its size, household needs may also depend on other factors, such as the age of each person and their disability status.

10. Evidence on income distribution and poverty in OECD countries provided in Burniaux et al. (1998), based on two alternative values of this elasticity (i.e. 1, whereby household income is divided by the number of household members, and 0.5 , whereby household income is divided by the square root of household size) suggests that alternative choices of equivalence scale have little impact on changes in aggregate inequality but a significant one on the relative position of groups of the population. 
- Third, "equivalising" household income implicitly assumes that the well-being that each person derives from an additional unit of income is independent of who in the household receives it. This is not always the case: for example, Mickelwright (2002), drawing on several empirical studies, argues that income transfers are more likely to be spent on child-related consumption when they are paid to the mother rather than to the father. This suggests that economic resources are not shared equally within the household.

Despite these problems, however, the assumption that some "sharing" of resources occurs within households seems preferable, for an assessment of well-being, to the assumption of no sharing.

28. In practice, several factors make the use of survey data problematic for comparisons of income levels across countries (Box 4). Methodological and conceptual differences in how household income is defined in household surveys and in the national accounts, together with other factors, imply that the value of household disposable income provided by surveys is generally lower than that measured by the national accounts, with large differences across countries. ${ }^{11}$ One way of avoiding problems in the comparability of national accounts and survey-based measures of household income is to "adjust" national accounts measure of household disposable income using survey-based data on the size of private households, applying a standard (but arbitrary) adjustment for household size. ${ }^{12}$

11. For example, across the 13 OECD countries for which information is currently available, the survey measure of (cash) household disposable income is equivalent to $73 \%$ of the total (cash and in-kind) household disposable income from the national accounts, with this ratio ranging between $97 \%$ in Norway and $42 \%$ in Mexico. This has implications for comparing levels of household income across countries: differences between the two measures will reflect both differences in income as measured by the two sources, and the methods used to adjust income for household size.

12. More specifically, the "equivalence" elasticity used is 0.5. This implies dividing the income of each household by the number of household members at the power of 0.5 . In the analysis below, the adjustment for household size is only "proximate", as it is applied to the (national-accounts-based) average values of per capita household disposable income; in general, the "true" impact of changes in household size will differ when applied to data for individual households. The adjustments are made using information from the OECD questionnaire on income distribution and poverty. As these data refer to discrete years that may differ across countries the data have been linearly interpolated between the available observations. 


\section{Box 4. Differences between national accounts and survey-measures of household income}

The measurement of household income in surveys differs in significant respects from that used for the purposes of the national accounts. Some of the main elements are:

- $\quad$ The scope of the reference population. National accounts refer to the resident population as derived from population censuses while surveys refer to private households (i.e. they exclude persons living in institutions). In addition, cross-country differences in weighting methods may impact on the population estimates provided by surveys relative to population censuses. On average, across the 19 OECD countries for which information is currently available, the population estimates used in household surveys are close to $98 \%$ of their national account counterpart, but lower (93\%) in Austria and New Zealand.

- $\quad$ The scope of the household sector. National accounts data available at the international level for the household sector include non-profit institutions serving households, while household surveys do not. Across the 13 OECD countries for which information is available, these non-profit institutions account for around $2 \%$ of the total household disposable income as measured in the national accounts, but up to $5 \%$ in Finland.

- The definition of income components. National accounts include in household income several non-cash components - such as income imputed for owner-occupied housing and for some types of financial assets - that surveys exclude; conversely, benefits from some retirement schemes are not included in household income in the national accounts while they are in surveys. Also, measures of self-employment income may differ between the two sources (because of the impact of depreciation allowances and of inventory accounting in the "tax" definition of self-employment income used in household surveys); these differences may be especially important for countries where unincorporated enterprises are very important.

- $\quad$ The frequency of surveys. While annual surveys exist in several OECD countries, there are exceptions; also, income may be measured over different time periods (e.g. weeks, months, fiscal and calendar years).

These methodological features account for a large part of the discrepancy between survey-based and nationalaccounts-based measures of household income. For example, a detailed comparison between the national-accounts and survey-based estimates of (gross) household income for Australia shows that accounting for differences in scope and concepts narrows the discrepancy between the two aggregates by $2 / 3$ (from $63 \%$ to $89 \%$, Siminski et al. 2003).

29. On this basis, equivalised household disposable income exceeds the non-equivalised measure, with the difference between the two being larger in countries with larger average household size. The correlation in country rankings based on the two income measures is 0.95 , suggesting that the unadjusted measure of household disposable income per capita is a good proxy for cross-country comparisons. When looking at changes in equivalised disposable income over time, reductions in family size have weakened economies of scale in consumption, so lowering the gains in equivalised income between 1995 and 2002 relative to those in non-equivalised income (Figure 11, right-hand panel). The adjustment for household size is significant for several countries and is larger when considering longer periods (left-hand panel). 
Figure 11. Real annual change of per capita household disposable income and adjustments for changes in household size, selected OECD countries
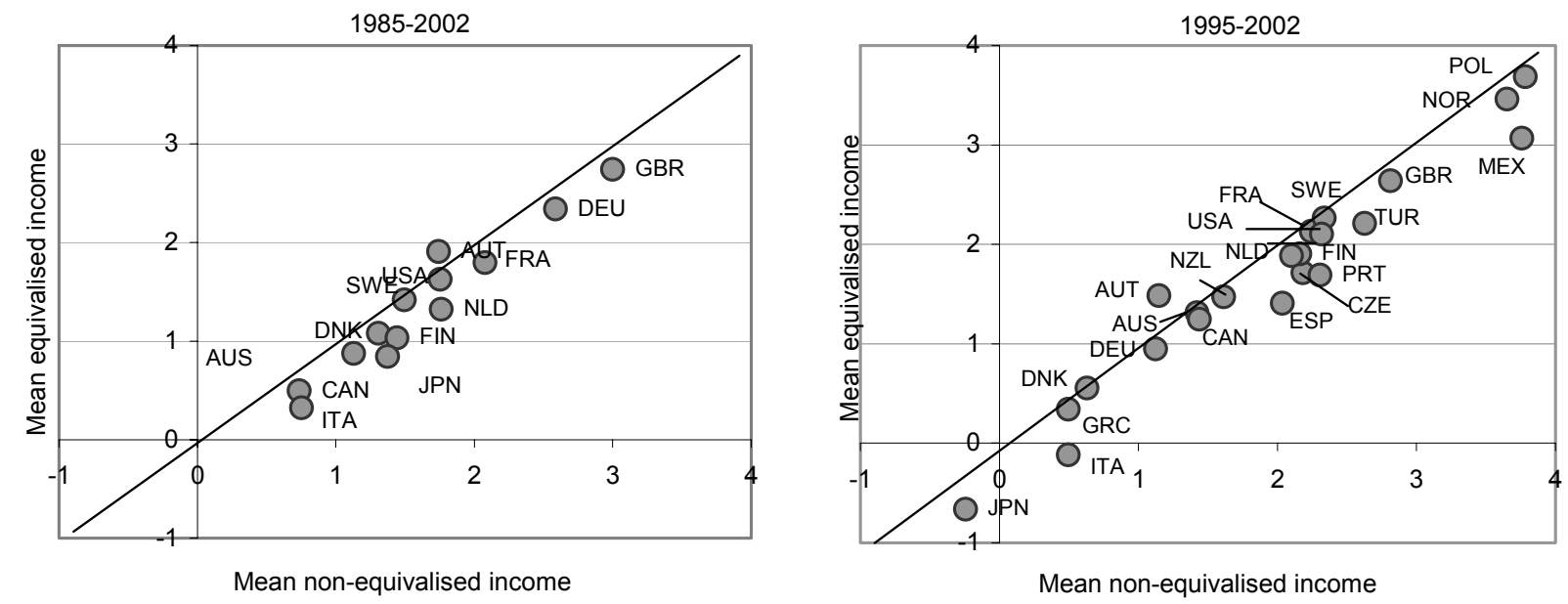

Notes: Survey data on household disposable income refer to discrete years (in the mid-1980s, mid-1990s and early 2000s) that may differ across countries. To allow comparisons between the years shown, these data have been interpolated between available observations and (when necessary) extrapolated to 2002. Data on the average size of private households (as available through these surveys) have been applied to the national account "aggregate" measure of household disposable income (to avoid the comparability problem of differences in the growth rate of survey- and national account based measures of household disposable income); because of this procedure, results differ from those that would be obtained by "equivalising" the income of each household and then averaging across individuals.

Source: Calculation on OECD National Accounts and OECD questionnaire on income distribution and poverty.

\subsection{Inequality in the distribution of economic resources}

30. Conventional measures of GDP attach the same weight to a unit of income, no matter the situation of the persons receiving it. Many theories of social justice depart, however, from this (implicit) value judgement, giving a greater weight to persons with fewer economic resources. While, in general, most approaches to social justice emphasise differences in life-time opportunities, the importance of economic inequalities for an assessment of well-being may be highlighted through the use of (more widely available) data on the distribution of current (household disposable) income. On the basis of these data, OECD-wide trends since the mid-1980s point to an increase in the Gini coefficient of income inequality of around 7\% on average, and higher is several OECD countries (Förster and Mira d'Ercole, 2005).

31. While different approaches have been suggested for "correcting" aggregate income measures for its inequality, this section relies on the approach suggested by Kolm (1969), which is based on the concept of "equally-distributed income" - the level of income which, if distributed equally, would give society the same level of well-being than its actual mean income in its present unequal distribution. ${ }^{13}$ This can be

13. The general form of this measure is:

$W=\left[\frac{1}{N} \sum_{i=1}^{N} y_{i}^{1-\varepsilon}\right]^{\frac{1}{1-\varepsilon}}$

where yi is the "equivalised" disposable income of person in the ith decile and $\varepsilon$ is a coefficient expressing the degree of aversion to inequality, i.e. how much income a society is willing to sacrifice to increase the equality of its distribution. The concept of "equally-distributed income" formalises the possible trade-off between increasing the level of total income in society and distributing it more equally at the cost of a 
computed under different assumptions as to the degree of aversion to inequality. Illustrative calculations of the potential impact of inequality are presented below using three values of the degree of aversion to inequality $(0,1$ and 10$)$, with greater values implying that a lower weight is given to high incomes. The three values chosen have an intuitive interpretation when considering the growth rates of "equallydistribute income": for a value of 0 (i.e. the standard measure of income), aggregate income growth is the average of the growth rates of each decile, with weights equal to the share of total income accruing to each: for a value of 1, aggregate income growth corresponds to the average of the growth rates of each decile, weighted by the share of persons in the total population; ${ }^{14}$ for a value of 10 , aggregate income growth correspond to the growth of the first decile of the distribution.

32. Based on these values of the degree of aversion to inequalities, two main patterns stand out:

- When looking at levels of "equally-distributed income" in 2002, the higher the aversion to inequality, the lower the level of "inequality-distributed" income (Figure 12). For a value of 1, the difference relative to the conventional income measure is, on average, around $15 \%$ but larger in some countries. Changes in country-rankings of "equally-distributed income", relative to those based on unadjusted data depend on the value used for aversion to inequality: they are small when using a value of 1 (a rank correlation of 0.98 ) but higher (a correlation of 0.77 ) based on a coefficient of 10 .

Figure 12. Levels of "equally-distributed" household disposable income for different values of the coefficient of aversion to inequality, 2002

US $\$$ at current PPP rates.

Countries sorted in ascending order of GDP per capita

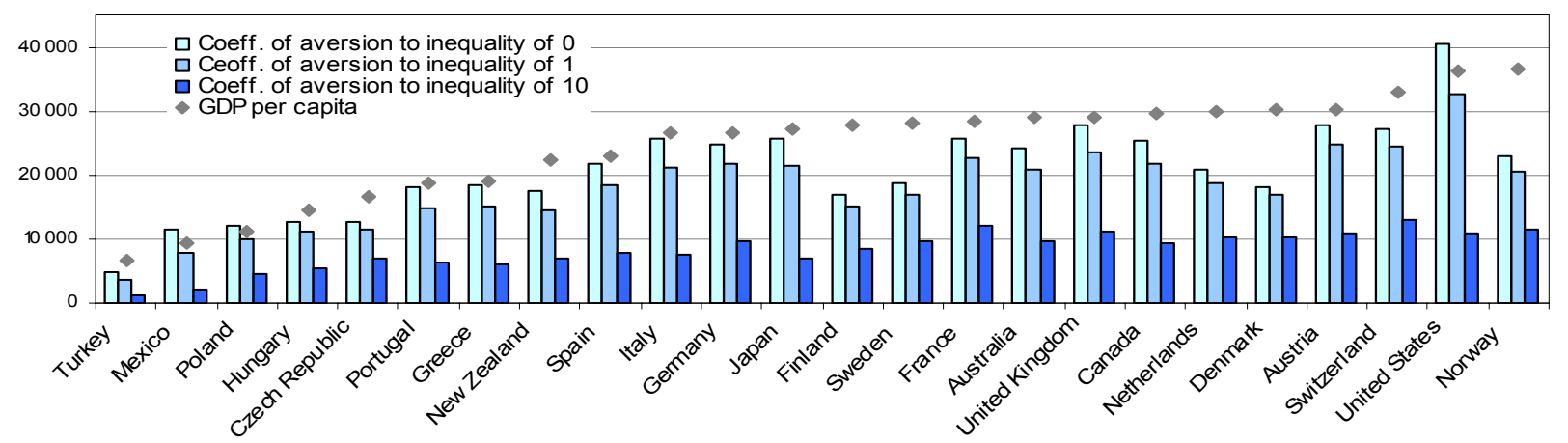

Notes. National values of "equally-distributed" household disposable income are computed as the average of the values for each decile, using coefficients of aversion to inequality of 0,1 and 10, respectively. Levels of household disposable income for each decile are computed as the product between national-account estimates of household disposable income, adjusted for household size, and survey-based estimates of the ratio between the disposable income of each decile to the mean. Data for household disposable income are converted into a common currency using PPPs for private consumption expenditures; data for GDP per capita are based on PPPs for GDP.

Source: Calculations based on OECD National Accounts and OECD questionnaire on income distribution and poverty.

lower overall efficiency. In this section, "equally-distributed income" is computed by applying to the national account measure of mean household disposable income per capita, adjusted for average household size, survey-based information on the distribution of household disposable income among deciles.

14. This implies, for example, that a $10 \%$ increase of the income of the bottom decile associated to a $10 \%$ reduction in that of the top will leave the average "equally-distributed income" unchanged (as compared to a decline - due to differences in average income between deciles - for a coefficient of 0 ). 
- Growth rates of "equally-distributed income" also depend on the assumed degree of inequality aversion. In general, differences in the annual growth rates of conventional and "equallydistributed" income increase with higher aversion to inequality (Annex Table A.1). For a coefficient equal to 1 , the average growth of "equally-distributed" income is $1.2 \%$, as compared to $1.4 \%$ for conventional income in the period 1985-2002. For a coefficient equal to 10 , the annual growth rate of "equally-distributed" income over the same period declines to $0.6 \%$.

Overall, while inequality can have a significant impact on well-being assessment relative to conventional income measures, its size crucially depend on the degree of aversion to inequalities that prevails in different societies.

\subsection{Summing up}

33. The various approaches described in this section to account for some of the factors that are omitted by conventional accounts are rooted in economic theory but different valuations of these items inevitably lead to different conclusions. Moreover, the "adjustments" described above ignore other factors that, while falling outside the boundaries of the national accounts, are potentially important for the wellbeing of individuals and communities (home production, defensive expenditures, environmental factors, Box 5). ${ }^{15}$ While measuring these items is hard and inevitably controversial, ignoring them may lead to misleading conclusions if they vary over time and across countries. This is particularly the case if policies affect the proportion of activities that take place in the market sector.

15. Nordhaus and Tobin (1972), in their seminal contribution on measures of economic welfare, adjust national accounts aggregates for leisure time, defensive and other intermediate expenditures, household production and some of the disamenities of urbanisation. Based on these various corrections, they conclude that their preferred measure of economic welfare per capita increased in the United States at an annual rate of 1\% from 1929 to 1965 , as compared to $1.7 \%$ in personal consumption per capita and $1.6 \%$ in net national product per capita. 


\section{Box 5. Environmental pressures and human well-being}

Concerns about environmental degradation have driven much of the research on "sustainable development" and on expanded measures of well-being. "Sustainable development" stresses the importance of both expanding the boundary of capital stocks considered by conventional accounts and of taking a broad view of human well-being, in which environmental and social elements are as important as economic ones. "Sustainable development" has direct implications for how income is measured. Conventional income and product accounts include the value of minerals and subsoil resources that are exchanged through markets but ignore those that are not. ${ }^{2}$ Beyond the natural resources that are drawn into the economy, land and ecosystems provide functions that are essential to human wellbeing: absorption of unwanted by-products of production and consumption, survival services that are essential for all human beings, and amenity services that improve quality of life. Valuing these functions, and bringing them to bear on economic decisions, is essential for achieving "development that lasts".

Despite significant progress in environmental conditions in several domains, OECD (2001) identified major environmental stresses in the state of biodiversity, declining fish stocks and tropical forest coverage, lower quality of groundwater and urban air, greater concentrations of chemicals in the environment and of greenhouse gases in the atmosphere. While physical measures pertaining to each of dimensions exist, they are not easily integrated into flowmeasures of economic resources. Practical steps that could be taken for better integrating physical measures of environmental stress within economic accounts are described in the 2003 Handbook on Integrated Environmental and Economic Accounts (SEEA).

1. This notion of "sustainable income" suggests that a measure of well-being should account for all stocks of capital (and other features such as population growth and technological progress that affect consumption possibilities) and by valuations that capture the social value of all goods (Nordhaus and Kokkelenberg, 1999).

2. Even in the case of assets (and related goods and services) that are exchanged through markets, conventional accounts exclude the impact of some resource discoveries and depreciation. However, discoveries are included in net worth as long as they are marketable. Natural disasters that destroy economic assets are also reflected in the value of net worth. 


\section{SELECTED SOCIAL CONDITIONS}

34. A complementary approach for assessing well-being is provided by social indicators. This section describes how indicators covering some specific aspects of well-being - selected with a view to provide a comprehensive description of social condition in OECD countries (OECD, 2005) - are related to conventional national accounts aggregates. In other terms, are OECD countries with higher GDP per capita also characterised by "better" social conditions? And do countries where GDP per capita increases the most also experience a more rapid improvement in these social conditions? The first section provides elements to answers these questions through simple correlation coefficients. The second question then explores to what extent performances based on the aggregation of these elementary indicators into a composite index of well-being differs from that based on GDP per capita.

\subsection{How closely related are social indicators and GDP?}

35. Figure 13 presents correlations between levels of 16 indicators of social outcomes and GDP per capita, for each of the four main categories of the OECD social indicators published in different issues of Society at a Glance, in the top panel; and between average annual changes of the two sets of variables, in the bottom. ${ }^{16}$ Figure 13 highlights a variety of patterns both within and between broad fields:

- With respect to self-sufficiency, there is in general a significant correlation across OECD countries between levels of GDP per capita and of employment rates (as well as for other selfsufficiency indicators, not shown in Figure 13, relating to the labour market). The correlation is not significant, however, for measures of how employment opportunities are shared within society (i.e. the extent of joblessness at the household level). The level of average years of schooling of the population aged 25 to 64 is significantly correlated with GDP per capita, although the correlation between changes in the two variables from 1980 to 2000 is insignificant. Conversely, mean performance of students aged 15, as assessed through the OECD Programme for International Student Assessment, is not significantly correlated to GDP per capita.

- With respect to equity, the Gini coefficient for the distribution of household disposable income tends to be higher in countries with lower per capita GDP, but the correlation is insignificant when excluding Mexico and Turkey. Similarly, since the mid-1980s, income inequality declined the most in countries that have recorded stronger growth in GDP per capita, but this mainly reflects the experience of Ireland. OECD countries with lower GDP per capita also record higher relative poverty, both among the entire population and among children, but patterns are less consistent when excluding Luxembourg and when looking at changes. ${ }^{17}$ A measure of gender

16. Within each of the four domains identified, there are differences in the extent to which the selected indicators capture different dimensions of well-being, which are reflected in their patterns of association. For example, in some areas (e.g. health) the different indicators are highly correlated with each other; in other areas (e.g. social cohesion) their correlation is significantly lower (Annex Table A.2). Indicators have been selected also on the basis of their availability, to allow for meaningful cross-country comparisons at a given point in time and over time. Levels of each social indicator are shown in Annex Table A.3.

17. While poverty rates are inconsistently related to levels of GDP per capita, there is a stronger link between GDP per capita and poverty thresholds. Changes in equity, however, are of interest for an assessment of 
equity in the paid labour market (the differences in median full-time earnings between women and men) is not correlated to GDP per capita, with gaps between countries at the same level of per capita GDP ranging between $10 \%$ and $40 \%$.

- A number of indicators of health outcomes are significantly correlated with per capita GDP: These include life-expectancy at birth, health-adjusted life-expectancy (a measure that combines information on both mortality and morbidity) and mortality risks, both among the entire population (i.e. estimates of the potential number of years lost) and among children. Differences in country performance in health outcomes are generally much smaller than those in GDP per capita but remain large: for example, infant mortality rates differ by a factor of around 2 between countries with similar per capita GDP. Correlations between changes in GDP per capita and in health conditions are generally insignificant.

- Indicators of social cohesion can refer to both its positive manifestations or to some of the pathologies that are informative about lack of cohesion, and which do have resonance as objectives of social policy. On the positive side, social relationships and participation in community life are important determinants of the extent to which individuals feel part of the broader community where they live. Research on "social capital" has stressed the importance of social relationships for subjective and community well-being, and of well-functioning democratic institutions for economic growth. While many of these findings remain controversial, the measure of participation in community life shown in Figure 13 - the share of people reporting that they volunteer in community groups - is higher in OECD countries with higher GDP per capita. On the negative side, indicators of crime victimisation, prisoners and suicides - as well as of divorces, drug use and road accidents - are not significantly correlated with GDP per capita. In terms of changes over time, OECD countries with higher growth in GDP per capita recorded statistically significant declines in the share of persons who had been victim of crime offences, although data refers to only 20 OECD countries.

To sum up, social indicators covering a broad range of components of well-being highlight significant cross-country correlations with GDP per capita in several cases, but insignificant correlations between changes in GDP per capita and in various social outcomes.

well-being irrespectively of how they co-vary with GDP per capita: Annex Table A.3 shows that income inequality and relative poverty rates - for the entire population and for children — increased slightly, on average, in the period 1985-2000. 
Figure 13. Cross-country correlations between per capita GDP and different social indicators in OECD countries

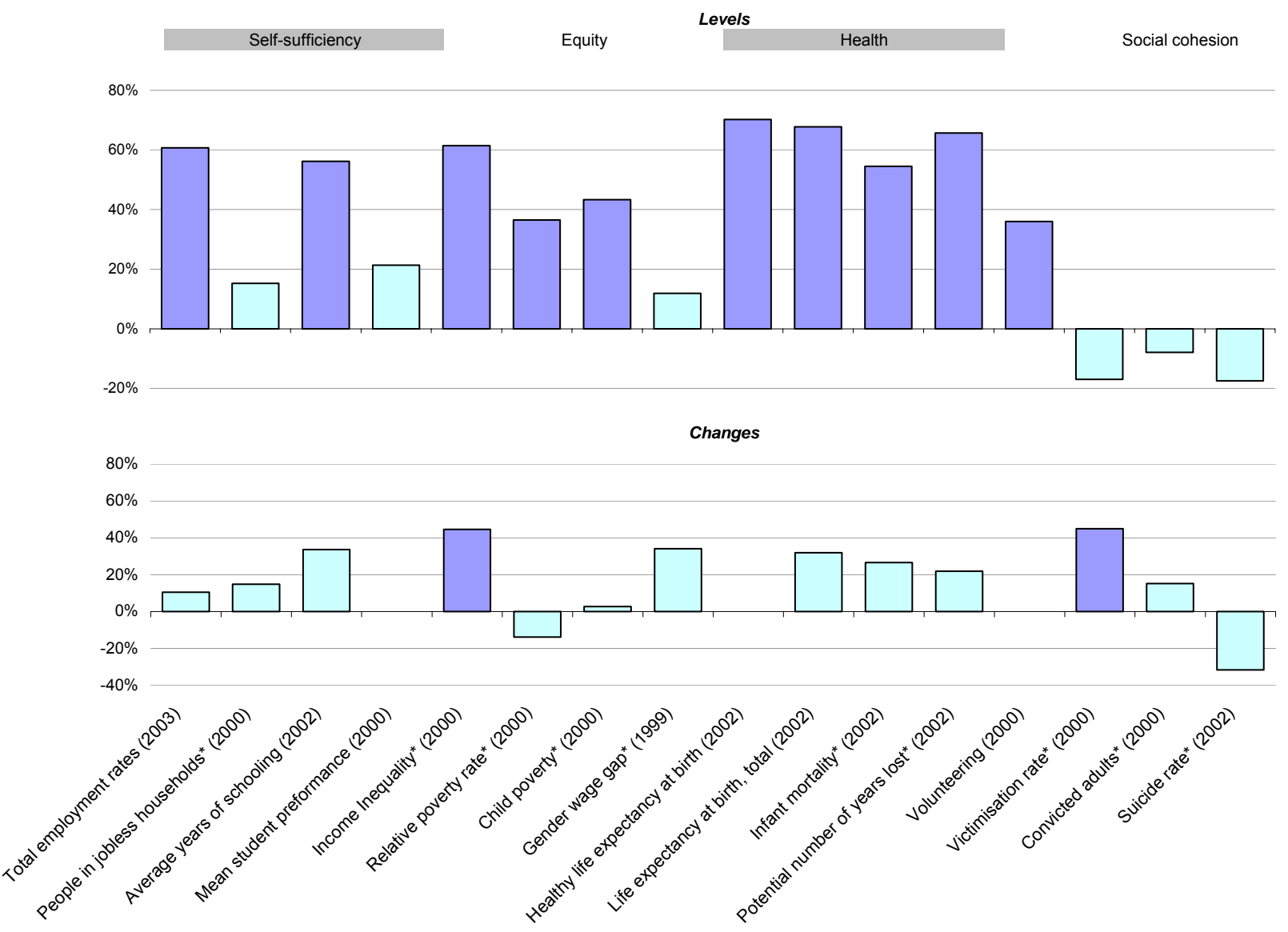

Note: Levels in the most recent year and annual percentage change over the periods. See Annex Table A.2 for an indication of the precise years. Pearson coefficient of correlation: bars in a darker colour indicate statistically significant correlations (at a $5 \%$ level).

For variables where higher values of the indicators denote worse social outcomes (e.g. infant mortality, prisoners, denoted with an "*") correlations with per capita income are shown with the opposite sign (e.g. countries with higher per capita income have lower infant mortality rate - shown with a positive sign — and higher rates of imprisonment shown with a negative sign). Per capita income is measured as GDP in current prices and purchasing power parity exchange rates, divided by the total population. Correlations are computed between values of the GDP per capita and of the social indicators in the same period; the number of countries considered may vary among different pairs of variables depending on data availability.

Source: Different issues of OECD Society at a Glance.

\subsection{Aggregation of social indicators into synthetic indexes of well-being}

36. The social indicators described above, while useful in identifying some potentially important dimensions of well-being, do not provide a synthetic measure that can be easily compared across countries and over time. One way of addressing this problem is normalising elementary indicators that are expressed in different units (e.g. dollars, years, quantitative scores, percentages of the population experiencing a particular condition) and vary over different intervals (e.g. unbounded measures of crime rates and 
bounded measures of poverty or unemployment rates); ${ }^{18}$ and aggregating them into a composite index. ${ }^{19}$ Assessments of well-being based on these composite indices will, however, depend on the choices made for selecting, normalising and weighting elementary indicators.

37. One way of illustrating the robustness of composite indices of well-being is through sensitivity analysis. Figure 14 presents data on the median value of the normalised score of a composite index based on the 16 social indicators described above, as well as its $90 \%$ confidence interval, based on 10000 trials where weights are assigned randomly to each of the elementary indicators, and compares these values to (normalised) GDP per capita in 2001. Luxembourg is excluded from the analysis, to avoid the bias in relative economic performance that would be associated to its "abnormally" high GDP per capita. On this basis, relative performance in terms of the social indicators is significantly different from one based on GDP per capita in slightly more than half of the countries. The correlation coefficient between (normalised) GDP per capita and the median value of the composite index is $0.76 .^{20}$

18. While several methods for normalisation exist, most synthetic indices of well-being rely on the "re-scaling" technique, whereby values of each elementary indicator are expressed as distance from the extremes of the sample (i.e. they vary between 0 and 1): in other words, values of the normalised score for each elementary indicator measure the performance of each country relative to the best- and worst-performers in the sample. With the re-scaling method, normalised scores are computes as:

$y_{i}^{j}=\frac{x_{i}^{j}-\min _{i}^{j}}{\max _{i}^{j}-\min _{i}^{j}}$

where $y$ is the normalised score of variable $x$ for country $j$, and min and max are the minimum and maximum values of the same indicators across all countries in the sample. Other normalisation methods can be derived by expressing each variable relative to its cross-country mean; to its maximum value; by dividing the distance between the variable and the mean by the standard deviation; or by taking the difference between the country-value of the variable in question and its minimum relative to its range. Maximum and minimum values can either be based on actual observations or be defined in "normative" ways (as policy goals).

19. The Annex, Section 5, describes the effects of normalisation and aggregation for each of the four main categories of social indicators. Practical guidance on the construction of composite indicators is provided by Hoffman et al. (2005).

20. Annex Table A.5 describes some of the better known composite measures of well-being, with a focus on those indicators that are available for several OECD countries, that provide information on changes in well-being and that have a focus on the social and economic dimensions. In general, despite their different methodologies, these composite indices highlight a common pattern of much smaller increases in wellbeing than in GDP per capita since the early 1970s and - often - of declines in recent years (Sharpe, 1999). While such conclusions are certainly dependent on measurement and weighting assumptions, a sensitivity analysis similar to the one performed in Figure 14 applied to the "index of economic wellBeing" of Osberg and Sharpe for seven OECD countries shows that this conclusion (i.e. gains in real GDP exceeding those in the composite index of well-being, for any possible choice of weights) is robust for some OECD countries but not for others. 
Figure 14. Median value and confidence interval of a composite index based on selected social indicators in OECD countries and GDP per capita

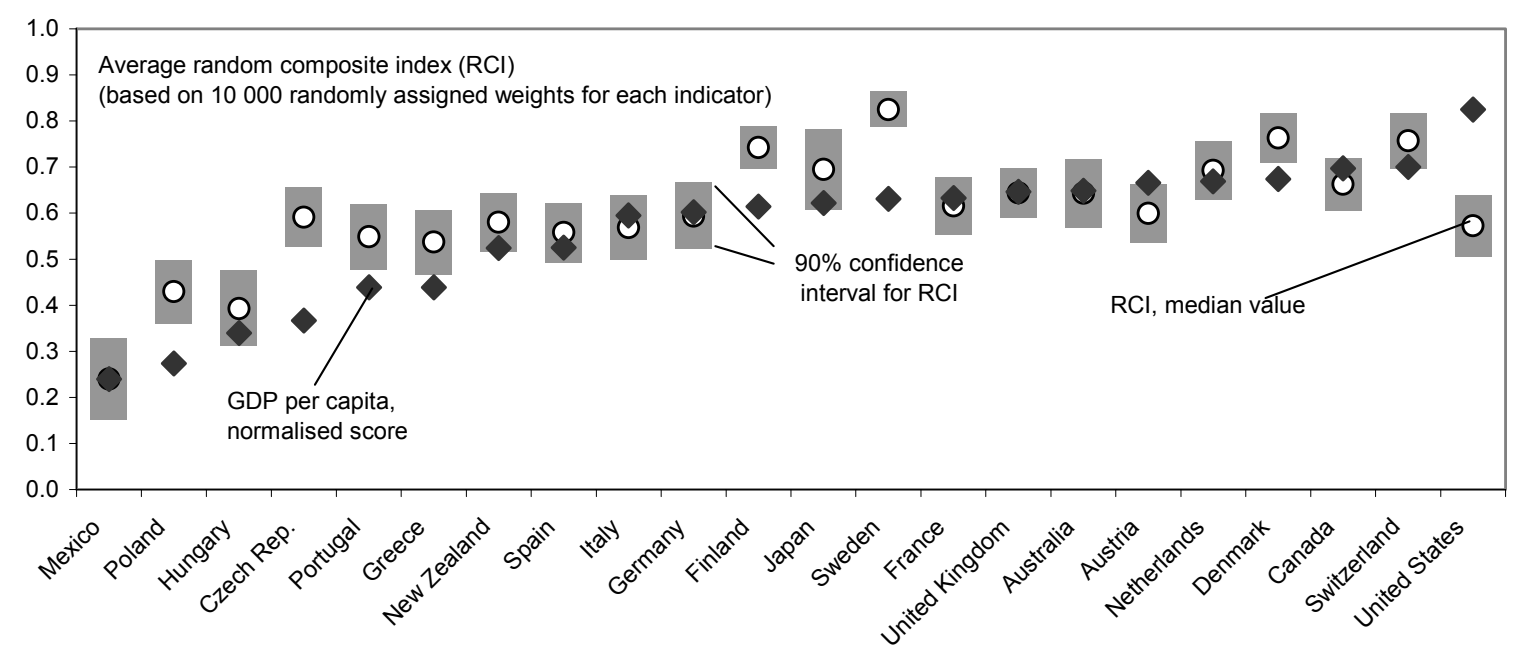

Note. The composite index is based on the most recent values of the 16 social indicators shown in Figure 13. The analysis is limited to OECD countries for which at least 13 of the 16 indicators were available. The composite index based on social indicators has not been rescaled within a 0-1 range in order to allow displaying a "confidence interval" for each country. In order to allow comparisons between the composite index of social indicators and GDP per capita, values of the latter have been rescaled on a range given by the minimum and maximum median values of the composite index.

Source : Calculations based on data in different issues of Society at a Glance - OECD Social Indicators. 


\section{SUBJECTIVE MEASURES OF HAPPINESS AND LIFE-SATISFACTION}

38. Subjective measures of life satisfaction are derived from surveys that ask individuals about their happiness and satisfaction with life as a whole or in separate domains (work, family, community life), generally in the context of interviews covering a broad range of fields. Different survey-based measures of subjective well-being in OECD countries around the year 2000 are shown in Figure $15 .^{21}$ The three indicators shown - mean life-satisfaction and happiness scores, and the share of respondents reporting to be very or fairly satisfied with their life - provide similar information and are correlated with each other (a correlation of at 0.85 or above). In general, the share of people reporting to be very or fairly happy with their life is above $90 \%$ in slightly less than $2 / 3$ of the countries, and significantly lower (at $75 \%$ or less) only in Turkey, Hungary and the Slovak Republic, while it is significantly lower in non-OECD countries. Measures of subjective well-being are, however, potentially affected by a range of measurement problems (Box 6). Also, cross-country correlations between subjective well-being and social indicators are as low as those for GDP per capita.

\section{Box 6. Statistical validity of subjective measures of life satisfaction}

The relevance of survey evidence on life satisfaction is a function of the statistical validity of the measures.

- $\quad$ Reviews on these subjective measures have concluded that they satisfy a number of desirable criteria (Frey and Stutzer, 2002). Studies have shown that individuals' reporting higher life-satisfaction are rated as happier by relatives and friends, tend to smile more during social interactions, have higher pre-frontal brain activity (the part of the brain associated with positive states), are more likely to recall positive life events and have higher resilience to stress (Layard, 2005). Multivariate analyses have shown that survey-measures of life satisfaction help to predict longevity and ill-being (depression, feeling of isolation, suicide), participation in community and political life, measures of job turnover and work absences.

- $\quad$ On the negative side, subjective measures of life-satisfaction may capture different underlying concepts (Deiner and Seligman, 2004), be subject to transient influences (Schwarz and Strack, 1999) and be affected by linguistic and cultural norms (Duncan, 2004). Because of small sample sizes and other survey features, data on subjective well-being from different surveys may differ even when they measure similar constructs. For example, data on the share of happy respondents as measured in the International Social Survey Programme for 2002, while significantly correlated to the values shown in Figure 15 (a correlation of 0.83 ) show some significant differences for some countries.

21. The data used in this section are based on the 1999-2001 wave of the World Values Survey. Lifesatisfaction data are based on replies to the question: "All things considered, how satisfied are you with your life as a whole these days?" Data on happiness refer to persons indicating to be "very" or "quite" happy (out of four possible modalities) in reply to a question on happiness with life as a whole. 
Figure 15. Different measures of subjective well-being in OECD countries, 2000

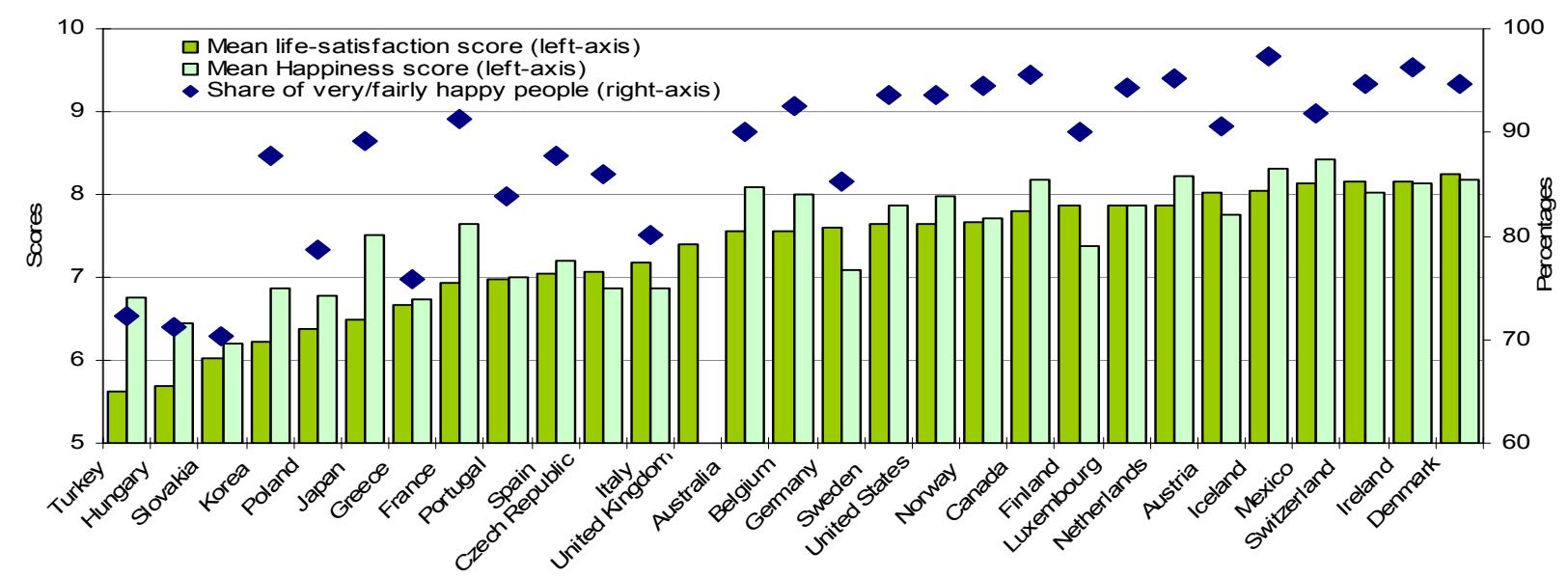

Notes: Countries are ranking (from left to right) in terms of increasing levels of the mean life-satisfaction score. Mean scores range between 0 and 10 .

Source. Calculations from World Values Survey, 1999-2001.

Figure 16. Cross-country relation between average life-satisfaction and GDP per capita in OECD countries, 2000

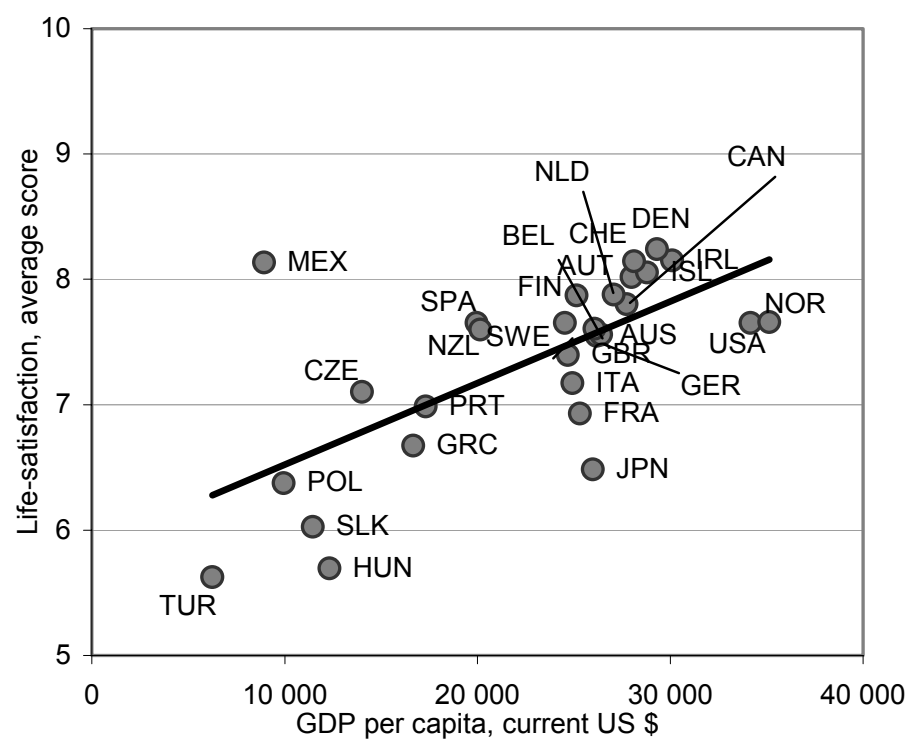

Notes: Data on life satisfaction are based on replies to the question: "All things considered, how satisfied are you with your life as a whole these days?" Average life-satisfaction is measured as the weighted sum of 10 satisfaction levels (from a level of zero, for persons reporting to be fully dissatisfied, to a level of 10, for those reporting to be fully satisfied) each weighted by the share of respondents indicating that level. GDP per capita is measured in US\$ at current PPP rates in 2000.

Source: Tabulations from the 1999-2001 World Values Surveys and World Bank, World Development Indicators, 2004. 
39. Some of the research on subjective life-satisfaction has looked at its relation to income at the level of individual countries. This research has highlighted two main patterns:

- First, across countries, Frey and Stutzer (2002) and several others have noted a positive correlation between subjective well-being and GDP per capita at a point in time, and a tendency for gains in subjective well-being to decline when GDP capita exceeds US\$10 000. Evidence of such a "flattening out" is less clear-cut when referring to OECD countries, with the shape of the relation depending on the countries included and the income-measure used (Figure 16).

- Second, across time, the coexistence of rapid rise in GDP per capita and stable levels of subjective well-being has been interpreted by several authors (Easterlin, 1974) as providing evidence that greater material prosperity does not bring higher happiness. However, this divergence may also reflect how the two constructs are measured (i.e. the comparison of an unbounded variable like GDP per capita to a bounded life satisfaction scores) ${ }^{22}$

40. While the conclusions about the link between income and subjective well-being that can de drawn from aggregate cross-country data remain controversial, firmer evidence is provided by research on the determinants of happiness and life-satisfaction at the level of individuals. In general, despite differences in approaches and modelling strategies, these studies highlight a remarkable similarity in the set of determinants of personal life-satisfaction: while some of these determinants are beyond the control of policies (e.g. genetic factors, personal experiences) others are not (e.g. having a job, family and community life). Two main results may be highlighted.

41. First, while research based on individual data typically finds evidence of a positive relation between life-satisfaction and people's own income, ${ }^{23}$ it also suggests that the differences in life-satisfaction across individuals are not proportional to differences in their income (Blanchflower and Oswald, 2003). Research also highlights that, when following individuals over time, changes in their income do not bring similar changes in their subjective well-being (Headey et al. 2004) ${ }^{24}$ Further, personal well-being depends strongly on the direction of income changes (Deiner and Seligman, 2004), a result that is consistent with experimental studies suggesting that the effect of income losses in reducing life-satisfaction is twice as large as that of an equivalent income gain (Layard, 2005). Some of factors that may account for the complexity of the relationship between income and life-satisfaction are described in Box 7.

22. Average life-satisfaction is generally measured as the weighted sum of 10 satisfaction levels (from a level of zero, for persons reporting to be fully dissatisfied, to a level of 10 , for those reporting to be fully satisfied) each weighted by the share of respondents indicating that level; hence, by construction, it is bounded by a value of 10. Van Praag (1991) observes that the use of a bounded-scale for self-reported well-being constraints the context of personal judgment and affect reported results.

23. The strength of the link between the two variables however varies considerably across studies: Diener and Biswas-Diener (2001) reports differences across estimates of the within-country correlation between income and subjective well-being ranging between 0.13 and 0.45 depending on the countries and periods considered, whether analysis rely on aggregate or individual income-data, and the covariates controlled for.

24. For example, Diener et al. (1993), based on U.S. data, conclude that the impact of income on life satisfaction is highest for persons earning less than US\$15 000 per year, and decreases steadily above this threshold; Frey and Stutzer (2002), based on Swiss data, also found that the impact of income on happiness declines for people in the top income class. 
42. Second, differences in the personal income of respondents explain little of the variance in subjective well-being across individuals, and less than that of a range of other factors. ${ }^{25}$ Research combining the use of individual and societal variables stresses the importance of some key non-financial correlates of well-being. These include work and joblessness (Layard, 2005); family relationships (Diener, 2000); health and education (Frey and Stutzer, 2002; Ross and Van Willigen, 1997); social ties and institutional quality (Helliwell, 2003); and income inequality (Alesina, et al. 2001). These research findings also suggest that the improvement in individuals' well-being due to these factors generally exceeds that associated to the financial gain that they may bring to individuals. In a number of cases, however, the non-financial correlates of subjective well-being identified by these studies are themselves significantly correlated to GDP per capita.

\section{Box 7. Adaptation, social comparisons and subjective life-satisfaction}

Two main factors have been invoked to account for the weak link between money income and life-satisfaction

- Adaptation of individuals to higher income. Kahneman (1999) distinguishes between two forms of adaptation. First, people get used to higher income as its effect on life-satisfaction evaporates over time ("hedonic treadmill"). Second, once basic needs are satisfied, aspirations increase with higher income ("satisfaction treadmill") but also become harder to fulfill, leading to unaccomplished goals and greater frustration. While evidence supporting the existence of "adaptation" has been provided by several empirical and experimental studies (Diener and Seligman, 2004; Layard, 2005; Van Praag and Frijters, 1999), these findings may also reflect the method used for eliciting judgments on personal satisfaction (i.e. use of a fixed number of categories for reporting survey responses even when income rises over time).

- Social comparisons among individuals. Several authors argue that subjective satisfaction is affected by comparisons between one's own situation and that of his or her peers. Research also suggests that social comparisons are stronger for individuals with higher income, and for those earning less than their reference group. Layard (2005) reviews evidence supporting the existence of social comparisons (e.g. US studies suggesting that perceived relative income matters more for personal well-being than one's own income, and Swiss studies showing that personal happiness depends only on one's own income relative to that of people living in the same community). Social comparisons may, however, also increase life-satisfaction, for example when it provides information on the prospects for own improvement (Senik, 2004).

43. Overall, while the research on subjective well-being is still in its infancy, it suggests that there are several distinct domains that contribute to overall life-satisfaction and that, beyond the private conditions of each individual, people's happiness also depend on the broader circumstances of the community and nations where they live.

25. For example, Di Tella and MacCulloch (2005) — based on happiness responses from almost 400000 people in the United States and Europe over the period 1975-97 — report that the increase in happiness associated to a $10 \%$ increase in GDP per capita is equivalent to that brought about by an increase in life expectancy of 1.4 years; by a decline in average unemployment rate of 1.7 points; by an increase in unemployment benefits of $6 \%$; by a fall in the divorce rate of $66 \%$; and by a drop in working hours of $4 \%$. 


\section{REFERENCES}

Ahmad, N. et al. (2003), Comparing Labour Productivity Growth in the OECD Area: the role of measurement, OECD Statistical Working Papers, STD/DOC(2003)5.

Alesina, A., R. Di Tella and R. MacCulloch (2001), "Inequality and Happiness: Are Europeans and American Different?", National Bureau of Economic Research Working Paper No. 8198, Cambridge.

Alesina, A., E. Glaeser and B. Sacerdote (2005), "Work and Leisure in the U.S. and Europe: Why so Different?”, National Bureau of Economic Research Working Paper No. 11278, Cambridge.

Arrow, K.J. (1951), Social Choice and Individual Values, New York.

Atkinson, A.B. (2005), Measurement of Government Output and Productivity for the National Accounts, Atkinson Review: Final Report, Palgrave-MacMillan.

Beckerman, W. (1978), Measures of Leisure, Equality and Welfare, OECD, Paris.

Blanchard, O. (2004), “The Economic Future of Europe”, Journal of Economic Perspectives, Vol. 18.

Blanchflower, D. and A. Oswald (2004), "Well-Being over time in Britain and in USA", Journal of Public Economics, Vol. 88.

Burniaux, J.M., T.-T. Dang, D. Fore, M.F. Förster, M. Mira d'Ercole and H. Oxley (1998), "Income Distribution and Poverty in Selected OECD Countries", OECD Economics Department Working Paper No 189.

Diener, E., E. Sandvik, L. Seidlitz and M. Diener (1993) "The Relationship between Income and Subjective Well-Being: Relative or Absolute?”, Social Indicators Research, Vol. 28.

Deiner, E. and M.E.P. Seligman (2004), "Beyond Money: Toward an Economy of Well-Being", Psycological Science in the Public Interest, Vol. 5.

Di Tella, R. and R. MacCulloch (2005), "Gross National Happiness as an Answer to the Easterlin Paradox?”, Economic Working Paper Archive at WUSTLE, April.

Duncan, G. (2005), "What Do We Mean By 'Happiness'? The Relevance of Subjective Wellbeing to Social Policy", Social Policy Journal Of New Zealand, Issue 25.

Duval, R. (2004), "Retirement Behaviour in OECD Countries: Impact of Old-age Pension Schemes and Other Social Transfer Programmes", OECD Economic Studies, No. 37, Paris.

Easterlin, R. (1974), "Does Economic Growth Improve the Human Lot? Some empirical evidence", in P. David and M. Reder (eds.), Nations and Households in Economic Growth: Essays in Honor of Moses Abramovitz, Academic Press, New York. 
EU, IMF, OECD, World Bank (1993), System of National Accounts, 1993, Brussles/Luxembourg. New York, Paris, Washington D.C.

Fleurbaey, M. (2003), "Peut-on mesurer le bien-être?”, in M. Debonneuil and L. Fontagné, (eds.) Competitivité, Conseil d'Analyse Économique, La Documentation Française.

Förster, M. and M. Mira d'Ercole (2005), "Income Distribution and Poverty in OECD Countries in the Second Half of the 1990s", OECD Social, Employment and Migration Working Papers No. 22, Paris.

Frey, B. S. and A. Stutzer (2002), Happiness \& Economics, Princeton University Press, Princeton and Oxford.

Gordon, R.J. (2004), “Two Centuries of Economic Growth: Europe Chasing the American Frontier”, mimeo, CEPR Discussion Paper No. 4415.

Headey, B., R. Muffels and M. Wooden (2004), "Well-Being over time in Britain and in USA", IZA Working Paper No .218.

Helliwell, J. F. (2003), "How's life? Combining individual and national variables to explain subjective well-being", Economic Modelling, No. 20.

Hicks J. R. (1940), “The valuation of Social Income”, Economica, Vol. 7.

Hoffman, A., E. Giovannini, M. Nardo, M. Saisana, A. Saltelli and S. Tarantola (2005), "Handbook on Constructing Composite Indicators: Methodology and User Guide", OECD Statistics Working Paper, Paris.

Inglehart, R. (2000), “Globalization and Postmodern Values”, The Washington Quarterly, Winter.

Kahneman, D. (1999), “Objective Happiness”, in D. Kahneman, E. Diener and N. Schwarz (eds.), Wellbeing - The Foundations of Hedonic Psychology, Russell Sage Foundation, New York.

Kolm, S. C. (1969), “The Optimal Production of Social Justice”, in J. Margolis and H. Guitton (eds.), Public Economics, Macmillan, London.

Landers, R.M., J.B. Rebitzer and L.J. Taylor (1996), "Rat Race Relax: Adverse Selection in the Determination of Work Hours in Law Firms", American Economic Review, Vol. 86.

Layard, R. (2005), Happiness - Lessons from a New Science, Penguin Press, New York.

Micklewright, J. (2002), "Social Exclusion and Children: A European View for a US Debate", Innocenti Working Paper No. 90, Florence.

Nordhaus, W.D. and E.C. Kokkelenberg (1999), Nature's Numbers - Expanding the National Economic Accounts to Include the Environment, National Research Council of the National Accademies, Washington D.C.

Nordhaus, W.D. and J. Tobin (1973), "Is Growth Obsolete?”, in Moss M. (ed.), The Measurement of Economic and Social Performance, Studies in Income and Wealth, vol. 38, National Bureau of Economic Research, Cambridge. 
OECD (2001), OECD Environmental Outlook, Paris.

OECD (2005), Society at a Glance - OECD Social Indicators, Paris.

Prescott, E.C. (2004), “Why do Americans work so much more than Europeans?”, National Bureau of Economic Research, Working Paper No. 10316, Cambridge.

Ross, C. and M. Van Willigen (1997) "Education and the subjective quality of life", Journal of Health and Social Behaviour, Vol. 38.

Samuleson, P. A. (1974), "An Essay on the $40^{\text {th }}$ Anniversary of the Hicks-Allen Revolution in Demand Theory", Journal of Economic Literature, Vol. 12.

Schreyer, P. and F. Koechlin (2002), "Purchasing Power Parities - measurement and uses", OECD Statistics Brief, No. 2.

Schreyer, P and D. Pilat (2001), "Measuring Productivity", OECD Economic Studies, No. 33, Paris.

Schwarz, N. and F. Strack (1999), "Reports of Subjective Well-Being: Judgmental Processes and Their Methodological Implications", in D. Kahneman, E. Diener and N. Schwarz (eds.), Well-being - The Foundations of Hedonic Psychology, Russell Sage Foundation, New York.

Senik, C. (2004), "When Information Dominates Comparison. Learning from Russian Subjective Panel Data", Journal of Public Economics, 2004, Vol. 88.

Sen, A. (1979), “The Welfare Basis of Real Income Comparisons: A Survey”, Journal of Economic Literature, Vol. XVII.

Sharpe, A. (1999), "A Survey of Indicators of Economic and Social Well-being", paper prepared for the Canadian Policy Research Networks, July.

Siminski, P. Saunders, S. Waseem and B. Bradbury (2003), "Reviewing the Intertemporal Consistency of ABS Household Income Data with External Aggregates", Australian Economic Review, Vol. 33.

Van Praag, B. and Frijters P. (1999), "The measurement of welfare and well-being: the Leyden Approach", in D. Kahneman, E. Diener and N. Schwarz (eds.), Well-being - The Foundations of Hedonic Psychology, Russell Sage Foundation, New York. 


\title{
ANNEX. SUPPORTING MATERIAL
}

\author{
Section 1. Additional Tables
}

Table A.1. Impact of changes in income distribution on the growth of real per capita household disposable income

\begin{tabular}{|c|c|c|c|c|c|c|}
\hline & \multicolumn{6}{|c|}{ Coefficient of aversion to Inequality } \\
\hline & \multicolumn{2}{|l|}{0} & \multicolumn{2}{|c|}{1} & \multicolumn{2}{|c|}{10} \\
\hline & 1985-2002 & $1995-2002$ & $1985-2002$ & $1995-2002$ & $1985-2002$ & $1995-2002$ \\
\hline Australia & 0.9 & 1.3 & 0.9 & 1.3 & 0.9 & 1.4 \\
\hline Austria & 1.9 & 1.5 & 1.8 & 1.2 & 0.3 & -1.6 \\
\hline Canada & 0.5 & 1.2 & 0.4 & 0.9 & 0.2 & -0.4 \\
\hline Czech Republic & .. & 1.7 & .. & 1.6 & .. & 1.2 \\
\hline Denmark & 1.1 & 0.6 & 1.1 & 0.4 & 1.1 & 0.0 \\
\hline Finland & 1.0 & 1.9 & 0.8 & 1.5 & 0.4 & 0.3 \\
\hline France & 1.8 & 2.1 & 1.8 & 2.2 & 2.2 & 2.1 \\
\hline Germany & 2.3 & 0.9 & 2.2 & 0.9 & 1.2 & 0.5 \\
\hline Greece & .. & 0.3 & .. & 0.2 & .. & 0.2 \\
\hline Hungary & .. & 4.4 & .. & 4.4 & .. & 3.4 \\
\hline Italy & 0.3 & -0.1 & 0.0 & 0.0 & -1.2 & 0.9 \\
\hline Japan & 0.8 & -0.6 & 0.5 & -1.0 & -1.0 & -2.7 \\
\hline Mexico & .. & 3.1 & .. & 4.0 & .. & 5.3 \\
\hline Netherlands & 1.3 & 1.9 & 1.2 & 2.0 & 0.4 & 2.0 \\
\hline New Zealand & .. & 1.4 & .. & 1.2 & .. & 1.0 \\
\hline Norway & .. & 3.5 & .. & 3.4 & .. & 4.5 \\
\hline Poland & .. & 3.7 & .. & 4.2 & .. & 4.4 \\
\hline Portugal & .. & 1.7 & .. & 1.8 & .. & 2.4 \\
\hline Spain & .. & 1.4 & .. & 1.7 & .. & 3.0 \\
\hline Sweden & 1.4 & 2.3 & 1.2 & 1.8 & 0.2 & 0.3 \\
\hline Turkey & .. & 2.2 & .. & 3.2 & .. & 3.0 \\
\hline United Kingdom & 2.7 & 2.6 & 2.5 & 2.4 & 1.4 & 1.6 \\
\hline United States & 1.6 & 2.1 & 1.5 & 2.2 & 1.3 & 1.8 \\
\hline Average & 1.4 & 1.8 & 1.2 & 1.8 & 0.6 & 1.5 \\
\hline
\end{tabular}

Notes. Data refer to equivalised household disposable income, based on national accounts data. Adjustments for inequality are based on Kolm's concept of "equally distributed" income, with values of the coefficient of aversion to inequality equal to 0,1 and 10 . The annual growth rate of "equally distributed" income coincides with that of household disposable income per capita, when using a coefficient of 0 ; with the arithmetic average of the growth rate of income across deciles, when using a coefficient of 1 ; with the growth rate of the income of the first decile, when using a coefficient of 10 . 
DELSA/ELSA/WD/SEM(2006)2

Table A.2. Correlation coefficients among social indicators within each of the four domains

Total employment rates

Share of persons in jobless households

Average years of schooling

Mean student performance

Relative poverty rates

Child poverty rates

Gini coeff. of income inequality

Gender wage gaps

Healthy life-expectancy at birth

Life-expectancy at birth

Infant mortality rates

Potential number of years lost

Participation in voluntary groups Victimisation rates

Suicide rates

Convicted adults in prisons

\begin{tabular}{|c|c|c|c|}
\hline \multicolumn{4}{|c|}{ Self-sufficiency } \\
\hline $\begin{array}{l}\text { Total employment } \\
\text { rates }\end{array}$ & $\begin{array}{l}\text { Share of persons in } \\
\text { jobless households }\end{array}$ & $\begin{array}{l}\text { Average years of } \\
\text { schooling }\end{array}$ & $\begin{array}{l}\text { Mean student } \\
\text { performance }\end{array}$ \\
\hline 1.00 & $(0.21)$ & 0.55 & 0.44 \\
\hline$(0.21)$ & 1.00 & 0.30 & 0.10 \\
\hline 0.55 & 0.30 & 1.00 & 0.56 \\
\hline 0.44 & 0.10 & 0.56 & 1.00 \\
\hline \multicolumn{4}{|c|}{ Equity } \\
\hline $\begin{array}{l}\text { Relative poverty } \\
\text { rates }\end{array}$ & Child poverty rates & $\begin{array}{c}\text { Gini coeff. of } \\
\text { income inequality }\end{array}$ & Gender wage gaps \\
\hline 1.00 & 0.86 & 0.87 & 0.27 \\
\hline 0.86 & 1.00 & 0.90 & 0.53 \\
\hline 0.87 & 0.90 & 1.00 & 0.41 \\
\hline 0.27 & 0.53 & 0.41 & 1.00 \\
\hline \multicolumn{4}{|c|}{ Health } \\
\hline $\begin{array}{l}\text { Healthy life- } \\
\text { expectancy at birth }\end{array}$ & $\begin{array}{l}\text { Life-expectancy at } \\
\text { birth }\end{array}$ & Infant mortality rates & $\begin{array}{c}\text { Potential number of } \\
\text { years lost }\end{array}$ \\
\hline 1.00 & 0.98 & $(0.72)$ & $(0.90)$ \\
\hline 0.98 & 1.00 & $(0.76)$ & $(0.88)$ \\
\hline$(0.72)$ & $(0.76)$ & 1.00 & 0.79 \\
\hline$(0.90)$ & $(0.88)$ & 0.79 & 1.00 \\
\hline \multicolumn{4}{|c|}{ Social cohesion } \\
\hline $\begin{array}{c}\text { Participation in } \\
\text { voluntary groups }\end{array}$ & Victimisation rates & Suicide rates & $\begin{array}{c}\text { Convicted adults in } \\
\text { prisons }\end{array}$ \\
\hline 1.00 & 0.59 & 0.39 & $(0.27)$ \\
\hline 0.59 & 1.00 & 0.01 & $(0.38)$ \\
\hline 0.39 & 0.01 & 1.00 & $(0.13)$ \\
\hline$(0.27)$ & $(0.38)$ & $(0.13)$ & 1.00 \\
\hline
\end{tabular}


Table A.3. Selected social indicators in OECD countries

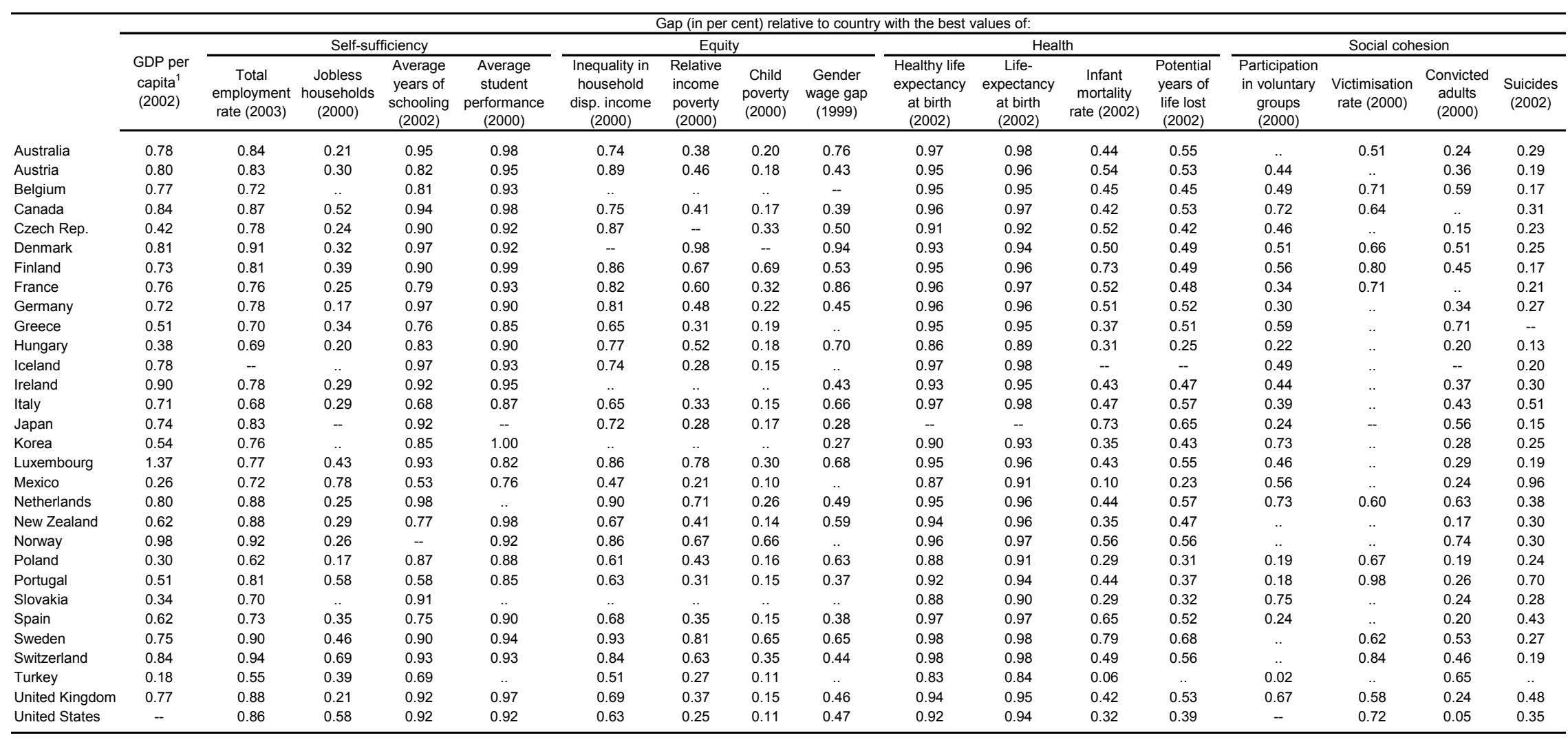

Legenda: The symbol ".." means "not available"; "--" denotes the country with the "best" performance in each indicator (i.e. the highest value in the case of indicators where higher scores imply higher well-being

(e.g. employment rates); the lowest value for indicators where lower scores imply higher well-being (e.g. share of persons in jobless households). For example, the total employment rate in Australia is $84 \%$ of that prevailing

(e. I. employment rates); the lowest value for indicators where lower scores imply higher well-being (e.g. share of persons in jobless households). For example, the total employment rate in Australia is $84 \%$, of
in Iceland (the country where this rate is the highest); while the share of individuals living in jobless households in Australia is 4.8 times (1/0.21) higher than in Japan (the country where this share is lowest).

1. Relative to the United States 
DELSA/ELSA/WD/SEM(2006)2

Table A.4. Composite measures of well-being in selected OECD countries

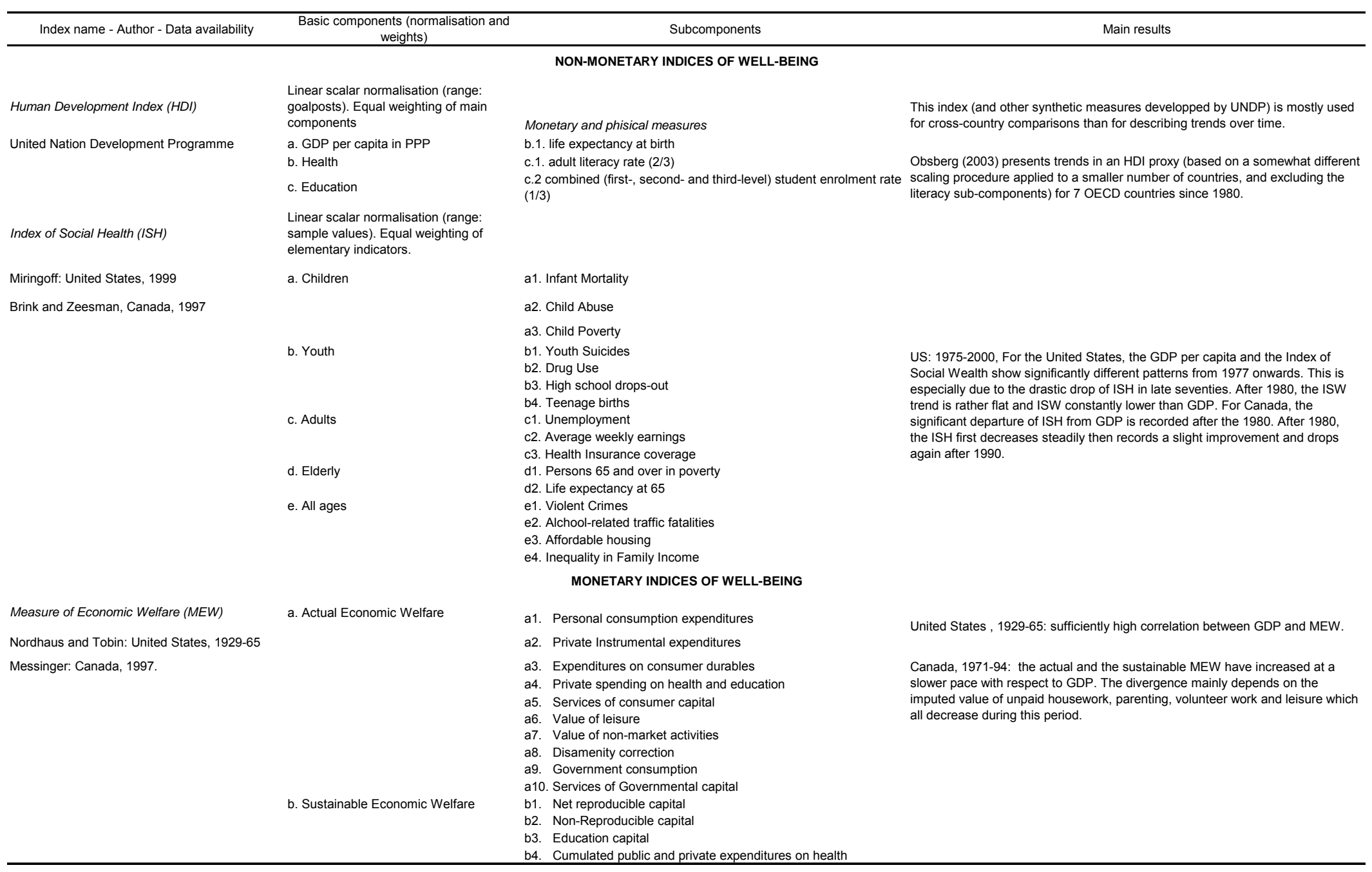


Table A.4. Composite measures of well-being in selected OECD countries (cont.)

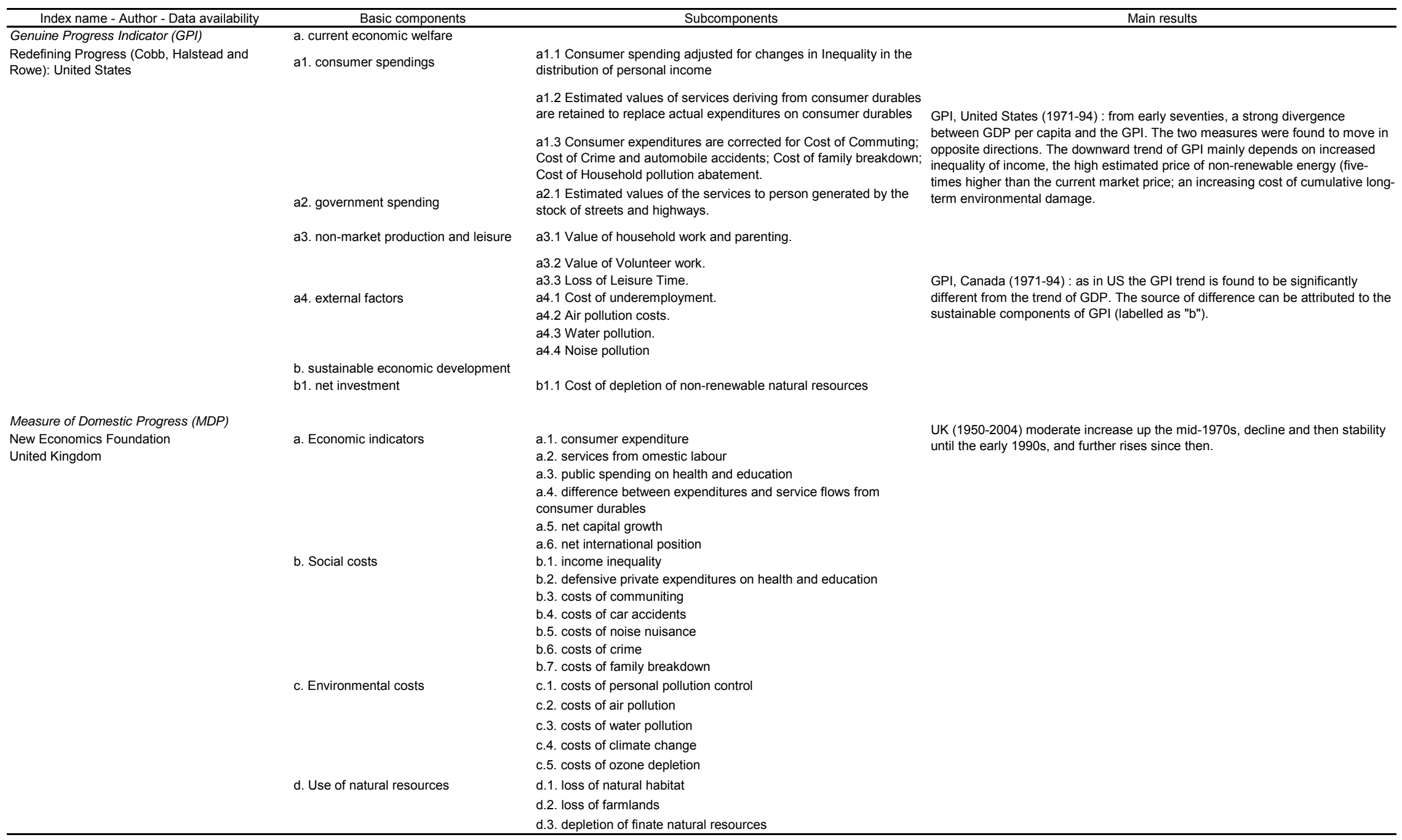


Table A.4. Composite measures of well-being in selected OECD countries (cont.)

DELSA/ELSA/WD/SEM(2006)2

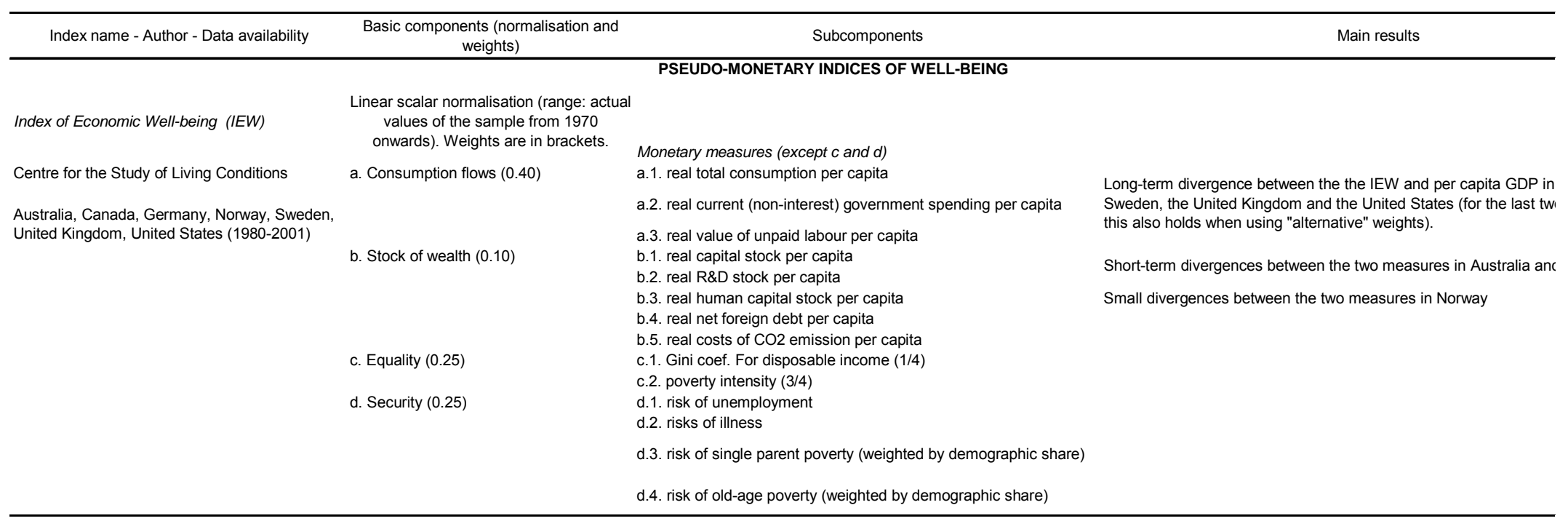




\section{Section 2. Accuracy of international comparisons of GDP}

44. National accounts estimates such as GDP are the result of combining a complex mixture of data from many sources, of which require adjustments (often using arbitrary methods) to be put onto a national accounts basis and to improve their coherence. It is therefore difficult to deliver an objective estimate of the "accuracy" of $\mathrm{GDP}^{26}$, and, even more, to assess the accuracy of international comparisons. International comparability is, in principle, ensured by the implementation of the "System of National Accounts" (SNA 1993). However, differences remain in the degree of implementation between OECD countries, in the practical methods used and, even more importantly, in the quality of the underlying statistical system.

45. Regarding growth rates of GDP, several known differences in statistical methods (relating to the use of hedonic pricing, treatment of software investment, military goods, financial services, volume aggregation) could have biased relative GDP growth rates between the United States, Europe and Japan in the second part of the 1990 s by up to $0.1 \%$ per annum each, albeit not always in the same direction (Ahmad et al., 2003). ${ }^{27}$ However, methods have tended to converge more recently.

46. Regarding levels of GDP, the situation is even more complex. To give an idea of the accuracy of OECD country estimates, it is common for GDP levels to be revised from 1 to 3 percentage points when new benchmark data are introduced (excluding conceptual changes). Some of the factors listed above (software, military goods and financial services) affect estimates of level of GDP at current prices, sometimes by several percentage points. Even more important are the differences in the capacity of statistical offices to provide an extensive coverage of their economies. Not all countries have strategic tools for statistics such as an extensive business register or access to quasi-exhaustive administrative sources. While all OECD countries recognise the need to measure and make adjustments for the "unobserved" economy, there is no guarantee that these adjustments are fully comparable between countries. Finally, the price data collected to allow for the calculation of GDP at "purchasing power parity" are less accurate than price indices used for any given country (i.e. it is more difficult to compare the price of a good or service between two countries at a given point in time than for the same country over time), reflecting inter alia the much smaller coverage of PPP surveys than for the compilation of national price indices. Overall, OECD statisticians considers that it is misleading to rank countries based on their GDP per capita at purchasing power parity when these are clustered within a range of less than 5 percentage points.

26. "Accuracy" is traditionally distinguished from "reliability", i.e. the difference between the first and later estimates of GDP. Objective measures of "reliability" of GDP are available for most OECD countries.

27. Among the various factors contributing to these differences is that no OECD country currently captures all non-observable activities (e.g. "illegal" outputs, such as drug trafficking and illegal gambling) in their estimates of GDP. As the scope of illegal activities varies between countries (e.g. in some countries gambling and prostitution are legal, while in others they are not) this further complicates comparability. 


\section{Section 3. Currency benchmarks and the use of Purchasing Power Parities}

47. One issue in cross-country comparisons of output, expenditure and income is how to convert values in different currencies into a common value. It has long been recognised that using market exchange rates can result in misleading estimates, the reason being that they do not reflect international price differences and that they are heavily influenced by short-term fluctuations. ${ }^{28}$ For these reasons, conversions using purchasing power parities (PPPs) are preferred over market exchange rates. The advantage with PPPs is that they equalise the purchasing power of different countries by eliminating the differences in price levels between countries. PPPs are relative measures, and the reference areas for PPP statistics issued by the OECD are either the OECD average or the United States.

48. Comparisons of the evolution of GDP volumes across countries and over time can be based on either current or on constant PPPs. Current PPPs compile and weigh together a new set of price data for every period. Thus, current PPPs imply that price structures are allowed to vary over time. Unfortunately, changes in the methodology of calculating the PPPs are also reflected in the volume estimates of GDP. Volume comparisons based on constant PPPs are done by fixing a base year and then extrapolating PPPs for the other years by applying the relative rates of inflation seen in the different countries. The result is that the price structure does not change over time and the comparisons only incorporate volume changes.

49. Looking at gaps in GDP per capita relative to the United States for OECD countries since 1970 shows that the estimates based on constant and current PPPs most often coincide (Annex Table A.5). However, the difference between the estimates is fairly large in the earlier years in Norway, Luxembourg, Switzerland, Denmark, United Kingdom and Iceland, and in recent years in the Netherlands, Spain and the United Kingdom. The reason is that, even if the volume of goods and services remains identical over time and across countries, a comparison based on current prices may reflect shifts in the structure of prices. ${ }^{29}$ This factor may be important when a country is a large producer and exporter of a good that experience large shifts in its price. For instance, large swings in the oil price may account for the difference in the two estimates in Norway in the 1970s and 1980s. In the most recent years ,ICT producing countries (Canada, Sweden, Finland and Korea) perform better when estimates are based on constant prices than on current prices reflecting a fall in the prices of ICT goods.

50. To sum up, for comparison at one point in time current PPPs are preferred over constant since they capture both volume and price changes. For comparison over time, current PPPs are from a methodological point correct but they introduce a stochastic element that may be more difficult to explain then the bias introduced by using constant PPPs. As a result, when combining cross-country comparisons and time-series analysis, the OECD tends increasingly to use constant PPP series.

28. See P. Schreyer and D. Pilat (2001), OECD Productivity Manual, Paris.

29. See P. Schreyer and F. Koechlin, (2002), "Purchasing Power Parities-measurement and uses, OECD Statistics Brief, No. 2. 
Table A.5. Gap in GDP per capita relative to the United States based on PPPs at current and constant (2000) prices

\begin{tabular}{|c|c|c|c|c|c|c|c|c|c|c|}
\hline \multicolumn{11}{|c|}{ Gap in GDP per capita relative to the US, percent } \\
\hline & \multicolumn{2}{|c|}{1970} & \multicolumn{2}{|c|}{1980} & \multicolumn{2}{|c|}{1990} & \multicolumn{2}{|c|}{2000} & \multicolumn{2}{|c|}{2003} \\
\hline & Constant & Current & Constant & Current & Constant & Current & Constant & Current & Constant & Current \\
\hline Luxembourg & -2 & -9 & -5 & -11 & 16 & 9 & 42 & 42 & 44 & 42 \\
\hline Norway & -22 & -36 & -5 & -21 & -5 & -22 & 5 & 5 & 5 & -2 \\
\hline Ireland & -55 & -54 & -51 & -49 & -45 & -44 & -18 & -17 & -10 & -11 \\
\hline Switzerland & 25 & 28 & 11 & 14 & 4 & 6 & -12 & -12 & -15 & -13 \\
\hline Austria & -26 & -25 & -16 & -15 & -18 & -17 & -18 & -18 & -17 & -18 \\
\hline Iceland & -32 & -29 & -9 & -6 & -15 & -12 & -18 & -18 & -18 & -21 \\
\hline Canada & -15 & -14 & -11 & -10 & -18 & -16 & -19 & -19 & -18 & -19 \\
\hline Denmark & -4 & -8 & -10 & -14 & -17 & -20 & -18 & -18 & -18 & -18 \\
\hline Australia & -13 & -12 & -19 & -18 & -26 & -27 & -23 & -23 & -20 & -19 \\
\hline Sweden & -11 & -10 & -16 & -15 & -19 & -18 & -22 & -22 & -21 & -23 \\
\hline United Kingdom & -26 & -29 & -28 & -30 & -27 & -28 & -26 & -26 & -24 & -20 \\
\hline Netherlands & -17 & -17 & -18 & -17 & -23 & -22 & -21 & -21 & -24 & -19 \\
\hline Finland & -32 & -32 & -24 & -24 & -22 & -21 & -26 & -26 & -24 & -25 \\
\hline France & -21 & -22 & -17 & -18 & -19 & -20 & -24 & -23 & -24 & -24 \\
\hline Belgium & -27 & -26 & -20 & -18 & -23 & -22 & -24 & -24 & -25 & -22 \\
\hline Japan & -34 & -34 & -26 & -27 & -18 & -18 & -25 & -25 & -25 & -25 \\
\hline Italy & -28 & -31 & -21 & -23 & -23 & -24 & -27 & -27 & -28 & -28 \\
\hline Germany $^{1}$ & & & & & -20 & -19 & -27 & -27 & -29 & -28 \\
\hline New Zealand & -20 & -19 & -31 & -31 & -38 & -39 & -41 & -41 & -37 & -38 \\
\hline Spain & -46 & -46 & -44 & -45 & -42 & -43 & -41 & -41 & -40 & -36 \\
\hline Korea & -84 & -84 & -78 & -78 & -64 & -64 & -53 & -53 & -48 & -49 \\
\hline Greece & -47 & -44 & -39 & -42 & -50 & -50 & -53 & -53 & -49 & -46 \\
\hline Portugal & -61 & -60 & -56 & -56 & -52 & -53 & -50 & -50 & -52 & -50 \\
\hline Czech Republic & & & & & -50 & -49 & -58 & -58 & -55 & -54 \\
\hline Hungary & & & & & & & -65 & -65 & -62 & -60 \\
\hline Slovak Republic & & & & & & & -69 & -69 & -65 & -65 \\
\hline Poland & & & & & -74 & -74 & -70 & -70 & -69 & -69 \\
\hline Mexico & -68 & -79 & -64 & -70 & -72 & -72 & -74 & -74 & -75 & -75 \\
\hline Turkey & -80 & & -81 & & -80 & & -80 & -80 & -81 & -81 \\
\hline
\end{tabular}

1) 1990 refers to 1992. 


\section{Section 4. Adjusting national account aggregates for leisure time}

51. While standard economic theory argues that any assessment of well-being should take leisure into account, there is not agreement on how to do this in practice (Beckerman, 1978). Some of the main issues to be addressed when trying to implement such adjustments include the following:

- First is whether the adjustment should relate to the leisure-time of the entire population or of workers. While past attempts have considered the entire population, the leisure of someone who is unemployed, or has involuntarily taken early retirement, is worth far less to them than the leisure time of a worker: indeed, they may well see their exclusion from the labour market as a curse, rather than a blessing. Because of this, it may be misleading to treat them in the same way.

- Second is how to measure the "quantity" of leisure. While this is often identified with "time spent outside paid-work", adjustments are needed for the time devoted to personal care, other workrelated activities such as commuting, as well as home production and other unpaid work. Good quality data to perform such adjustments are most often lacking.

- Third is how to "value" leisure. Valuation based on GDP per hour worked provides a measure that is more representative of the societal benefits (in terms of higher GDP) that would derive from different choices on working hours. Valuation based on hourly earnings is more relevant from the perspective as assessing the work-leisure choices of individual workers.

- Fourth is whether estimates of leisure should reflect the higher productivity that could follow technological progress and greater availability of consumer durables. Different assumptions on the productivity of leisure (i.e. the notion that same quantity of leisure time brings more utility to workers today than in the past) translate in different ways of "deflating" the earnings-based values of leisure in the terminal year: deflation based on wage-inflation implies no productivity gains; deflation based on price-inflation implies "crediting" leisure with the gain in hourly labour productivity. While, empirically, these different assumptions have a large impact on results, there is little a priori ground for choosing between these two extremes.

- Last, is how to adjust changes in real GDP for changes in leisure time. The approach followed by Nordhaus and Tobin (1976) adds the value of leisure at constant prices to real GDP in both the initial and final year: as growth in leisure-time tends to be less than for real GDP (in the absence of productivity adjustments) the resulting "leisure adjusted" aggregate will typically increase by less than real GDP (the more so the larger the size of leisure relative to GDP). The approach suggested by Usher (1973) adds the change in leisure-time to real GDP in the final year: when leisure increases over time, growth of "leisure-adjusted" GDP will exceed that of real GDP, even in the absence of productivity adjustments.

52. Illustrative estimates of the impact of leisure time on GDP per capita are presented in Figure 10 of the main text, for levels in 2001, and in Annex Table A.6, for changes since 1970. These estimates embody specific assumptions on each of the issues described above: i) estimates focus on leisure of persons at work rather than of the population at large; ii) the quantity of leisure time is measured by deducting from the time endowment of each worker a (common) estimate of the time devoted to personal care and unpaid activities and (country and year specific) estimates of the annual working hours per worker, ${ }^{30}$ iii) leisure time is valued using three different prices: GDP per hour worked; hourly

30. The share of time devoted to personal care and other unpaid activities outside is kept unchanged over time in all countries because of lack of suitable time-use data for different years. Data in annual hours worked per employee are derived from the OECD Productivity Database. Estimates of the number of hours 
compensation of employees; and half of hourly compensation, an arbitrary assumption to allow for the possibility that cross-country differences in hours worked reflect not just different preferences but also policy distortions; iv) when looking at changes in leisure over time, one of the estimates allows for productivity increases: this is done by using the GDP deflator to convert the earnings-based estimates of leisure into constant prices; and $v$ ) corrections of real GDP per capita are done using the Usher's approach, i.e. by "adding" the change in leisure time to GDP per capita in the final year. Findings are described in the main body of the text.

devoted to personal care (sleep and other personal care activities) and to other "committed" activities (such as commuting, housework, care-giving) are based on information on the share of time (48\% and 17\%) devoted to these activities by workers in the early-2000s in a sample of OECD countries. These data are derived from the Australian Time Use Survey for 1997; the Canadian General Social Survey-Time Use for 1998; the Harmonised European Time Use Survey for 2004, the Japanese Survey on Time Use and Leisure Activities of 2001, the New Zealand Time Use Survey for 1999 and the American Time Use Survey of 2003. 
DELSA/ELSA/WD/SEM(2006)2

Table A.6. Impact of changes in the amount of leisure time of workers on the annual growth of real per capita GDP

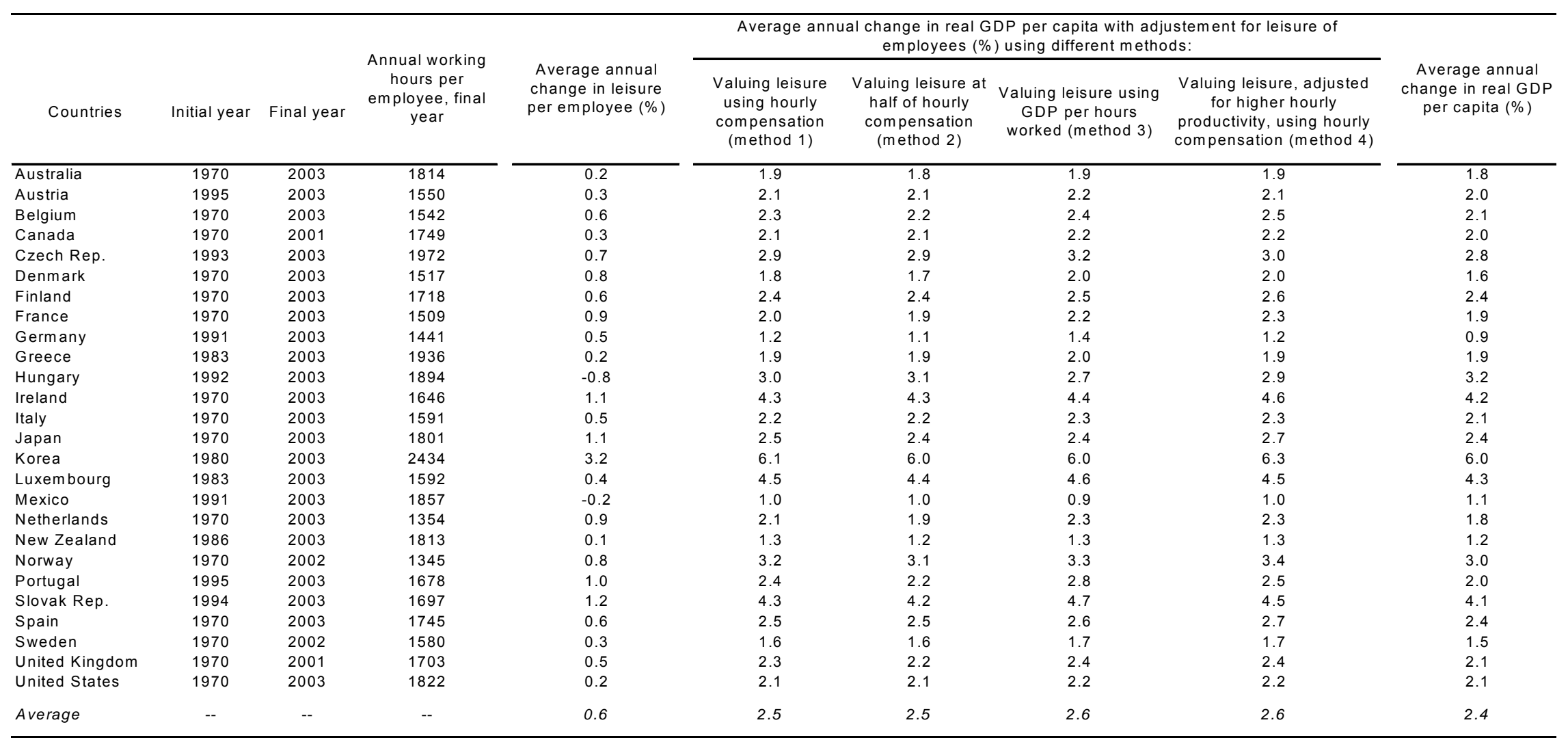

Notes: Annual changes in "leisure adjusted" real GDP per capita are calculated by adding the value of changes in leisure time to GDP per capita in the final year. Estimates of the amount of leisure time of workers in each country are calculated by deducting from the time endowment of each worker (365 days times 24 hours) common estimates of the time spent sleeping and for personal care ( $48 \%$ of the time endowment) and for commuting, other work-related activities and unpaid work ( $17 \%$ of the time endowment) and country-specific data on annual working hours of employees. Annual growth rates in "leisure-adjusted" real GDP per capita are derived using different methods: valuing leisure using hourly compensation in the base year (method 1); half of hourly compensation in the base year (method 2); GDP per hour worked in the base year (method 3); and applying current hourly compensation deflated by the GDP deflator. These monetary values of leisure time at constant prices, after being multiplied by the share of worker in the total population, are added to GDP per capita at constant prices in the final year.

Source: OECD productivity database for data on annual working hours, compensation of employees and nominal GDP; OECD analytic database for data on dependent employment and GDP deflators. 


\section{Section 5. Synthetic measures of well-being: normalisation and weighting of four categories of OECD social indicators}

\section{Introduction}

53. One way to provide a parsimonious and yet meaningful representation of social conditions is through the aggregation of the relevant indicators into a single synthetic index. This section illustrates one approach to the construction and graphic representation of such synthetic indexes, for each of the four categories of social indicators used in the OECD classification. It then describes the consequences of different choices as to the weight applied to elementary indicators within each of these four categories. Because of limited time-series data for several of the OECD social indicators, the analysis is limited to data referring to the most recent year.

\section{Aggregation using equal weights for each indicator}

54. The issues surrounding the construction of synthetic index are not specific to the measurement of social condition, but present themselves in a variety of fields. A standard procedure for confronting variables expressed in different units (e.g. life expectancy, mortality rates etc.) is to "normalise" each indicator within a range between 0 and 1 - i.e. comparing each country to the best and worst performer in a given year. ${ }^{31}$ This procedure is applied here to the 16 social indicators presented in Figure 13 of the main text (and Annex Table A.3), separately for each of the four categories of "self-sufficiency", "equity", "health" and "social cohesion". For each country, these normalised values are averaged and the resulting value is re-scaled on a $0-1$ range. ${ }^{32}$

55. For each category of social indicators, these "normalised scores" can be compared to the (normalised) score of GDP per capita, so as to highlight the domains where social performance departs more significantly from the economic performance of each country. ${ }^{33}$ Annex Figure A.1 shows four pairwise comparisons, with countries ordered (anti clockwise) in declining order of (normalised) GDP per capita (i.e. Luxembourg, the country with highest GDP per capita has a value of 1 and Turkey, with the lowest GDP per capita, a value of 0 ). When countries' performance in their synthetic social index is very similar to that based on per capita GDP, the two "snails" move alongside each other. Conversely, the crossing of the two snails indicate that countries' performance based on GDP per capita is significantly different from that based on social indicators. Main findings for each of the four domains of social indicators are summarised below.

31. While in some application these minimum and maximum values have an explicit normative meaning (e.g. the Human Development Index characterised them as "goalposts"), this approach is used here only for descriptive purposes.

32. As country values for some indicators are sometimes missing, the analysis is limited to countries where at least two indicators for each category are available.

33. An alternative approach to the construction of a synthetic index is based on "normalised country-ranks", an approach which is however more sensitive to missing values. 


\section{Self-sufficiency}

56. There are, in general, significant discordances between the synthetic index of self-sufficiency and GDP pre capita (top, left-hand panel). ${ }^{34}$ This divergence is most evident in the case of Luxembourg, where the highest level of per capita GDP is matched by a below-average self-sufficiency index (due to comparatively low student performance and a low employment rate); and, to a lower extent, of Italy (mainly because of low employment rates), Germany, France and Austria (all characterised by high proportions of people living in jobless households). High values of the synthetic measure of selfsufficiency are recorded by Japan and Korea, the Nordic countries, as well as Canada and New Zealand all countries that perform better in this dimension than in terms of per capita GDP.

\section{Equity}

57. There are also significant differences in country performance based on GDP per capita and the synthetic index for equity (top, right-hand panel). ${ }^{35}$ Nordic countries rank unambiguously as best performers, while Poland, Hungary and the Czech Republic also record relatively high scores. ${ }^{36}$ The United States stand out for its relatively poor performance in terms of equity, mainly on account of its high poverty rates both among the entire population and among children (the second highest levels among OECD countries). Japan also displays a relatively low performance in equity, mainly because of very high gaps in wages by gender (almost twice the OECD average).

\section{Health}

58. Around half of all OECD countries have a score in the synthetic health index (bottom, left-hand panel) above 0.8 . This points to much homogeneity in health outcomes and to a significant distance from the two countries at the bottom of the league (Turkey and Mexico). The synthetic index for health is in general highly correlated with the normalised score of per capita GDP; as a result, the "snails" corresponding to the two indexes never cross with each other - implying that all countries have a better performance, relative to the country at the bottom of the league, in health than in GDP per capita. The United States is the main exception to this pattern, with a value of the synthetic health index that is equal to that based on GDP per capita, and significantly lower that of a majority of OECD countries. The best health performance is recorded by Japan and Iceland, while most European countries display a comparable health performance - with the partial exception of Portugal and eastern European countries, where health performance is significantly lower.

34. Due to lack of data, the self-sufficiency synthetic index excludes values of average student performance data for Turkey and the Netherlands; of people in jobless households for Korea and Iceland; of average student performance and people in jobless households for the Slovak Republic.

35. The synthetic index of equity was not computed for Belgium, Ireland, Korea and Slovak Republic, because of lack of three of the indicators; in the case of Turkey, Mexico, Island, Greece and Norway, the synthetic index excludes measures of gender wage gaps.

36. The good performance in the synthetic index of equity for the Czech Republic and Hungary is mainly explained by their low poverty rate, low income inequality, and (for the Czech Republic) a very low poverty among children; in the case of Poland, it reflect low poverty rate among children and small wage gaps between genders. All these positive outcomes reflect the "relative" nature of these indicators: consideration of "absolute" measure of poverty would significantly lower the synthetic index of these countries. 


\section{Social cohesion}

59. Patterns of association between the synthetic index of social cohesion and per capita GDP (bottom, right-hand panel) differ significantly among, respectively, "richer" and "poorer" OECD countries. ${ }^{37}$ Among countries with higher values of the normalised GDP score, the relation between the two indexes is generally quite tight, with the main exception of Luxembourg, whose performance in terms of social cohesion is significantly lower than that based on normalised GDP per capita. Sweden, the Netherlands and Mexico record a significantly better score in social cohesion than in per capita GDP: for the first two countries, this mainly reflects high participation in voluntary activity and low rate of convicted persons, while in Mexico this reflects the second highest level of subjective life-satisfaction and the second lowest rate of suicides among OECD countries. France and Japan rank lower in terms of their index of social cohesion than for GDP scores.

Figure A.1. Synthetic indexes of social conditions and GDP per capita, most recent year
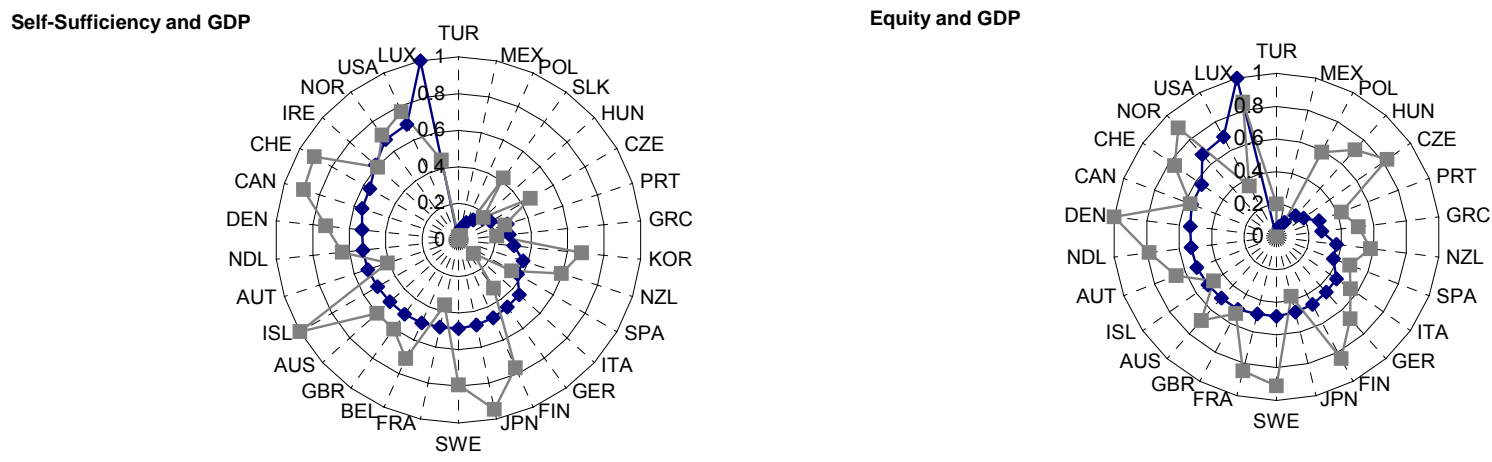

- GDP normalised score
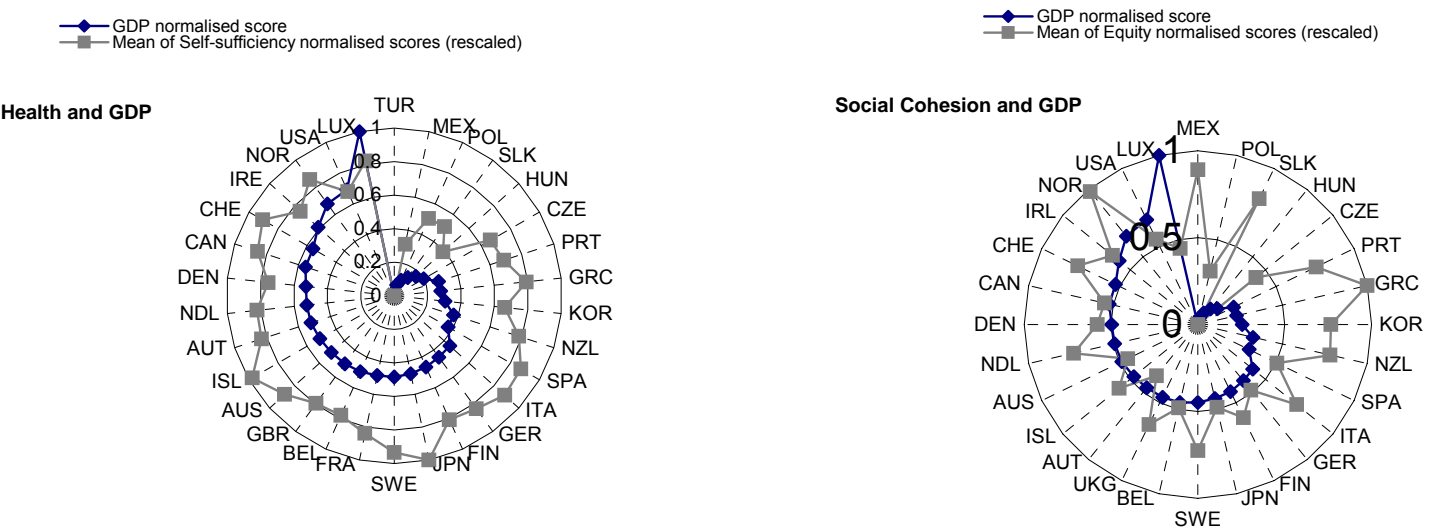

GDP normalised score

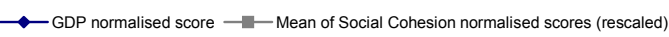

Source: Calculations based on data in different issues of Society at a Glance-OECD Social Indicators, Paris.

37. Because of lack of data, the synthetic index of social cohesion exclude values of life-satisfaction for New Zealand; participation in voluntary groups for Australia, New Zealand, Norway and Poland; convicted population for Canada and France; and suicides for Turkey. 


\section{The impact of alternative weighting schemes}

60. The impact of different choices as to the weight applied to individual indicators, within each of the four main categories, can be illustrated through sensitivity analysis, in a similar way to that applied in Figure 14 of the main text to all 16 social indicators. Annex Figure A.2 shows the median values and the $90 \%$ confidence interval corresponding to 10000 random trials where different weights are assigned to the indicators belonging to each of the four categories of social indicators.

61. The random weights exercise shows that the assessment of countries relative performance in terms of social conditions depends on arbitrary choices of weights in some cases but not in others. In the case of health (bottom, left hand-panel) confidence intervals are quite small for most of the countries considered, with the median value of the health index significantly above (normalised) GDP per capita in all countries except the United States. In the case of equity (top, right-hand panel) confidence intervals are small for most countries, with the main exception of Greece, Japan, Iceland and Norway; in the case of Greece and Japan, where relative performance in the (median) equity indicator is respectively higher and lower than in GDP per capita, the (normalised) GDP score falls within the confidence interval of the equity indicator (i.e. there is no significant difference between the two). Confidence intervals are significantly larger in the case of the self-sufficiency (top, right-hand panel) and social cohesion (bottom, left-hand panel) indicators, reflecting larger differences in country performance with respect to each of the elementary indicators included in the set.

Figure A.2. Median value and confidence interval of composite indexes for four categories of social indicators in OECD countries and GDP per capita.
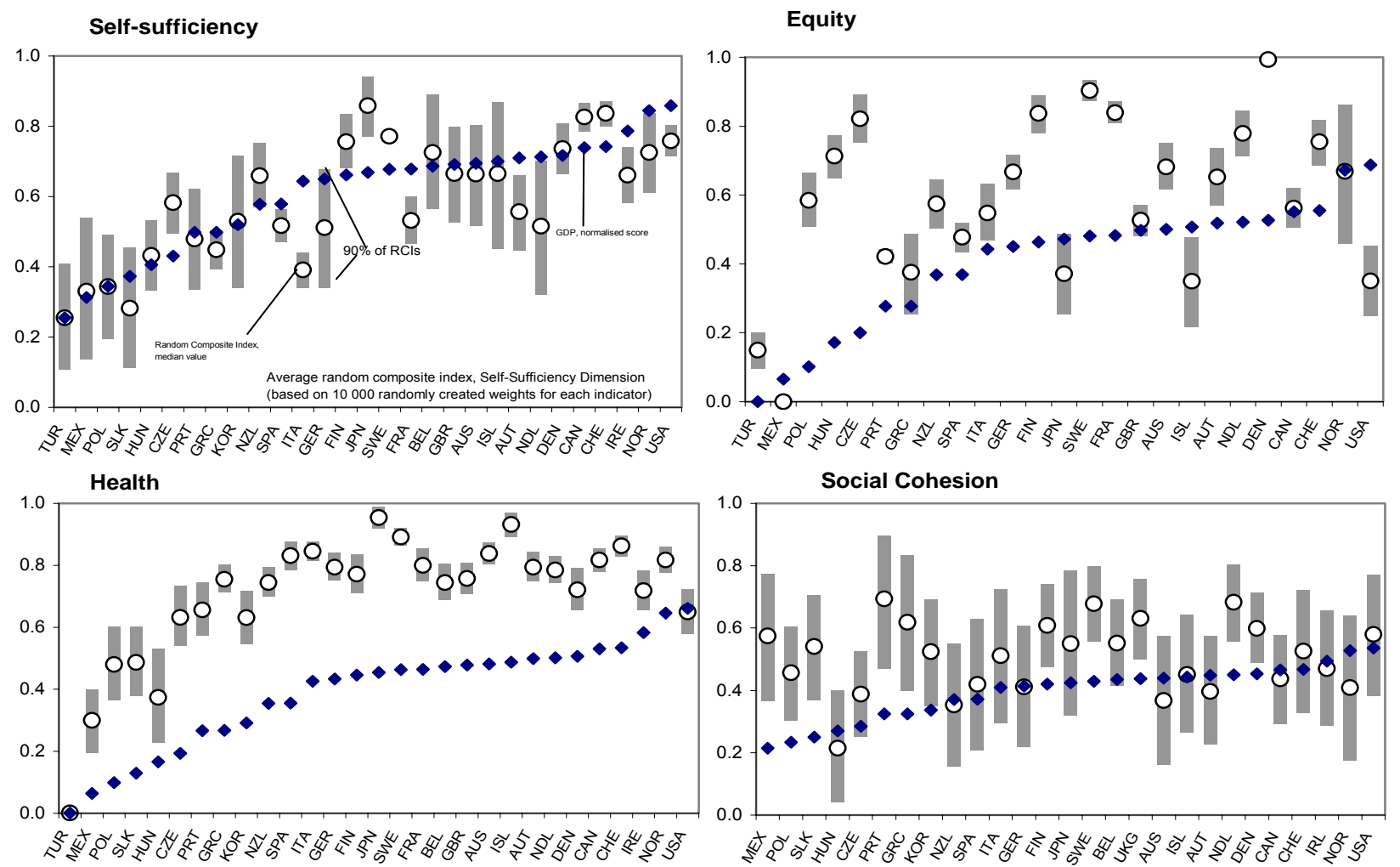

Note. The composite index based on social indicators has not been rescaled within a 0-1 range in order to allow displaying a "confidence interval" for each country. In order to allow comparisons between the composite index of social indicators and GDP per capita, values of the latter have been rescaled on a range given by the minimum and maximum median values of the composite index.

Source: Calculations based on data in different issues of Society at a Glance - OECD Social Indicators, Paris. 


\section{OECD SOCIAL, EMPLOYMENT AND MIGRATION WORKING PAPERS}

Most recent releases are:

No: 32 SOCIAL DISADVANTAGE AND EDUCATION EXPERIENCES (2006)

Stephen Machin

No. 31 CAN PARENTS AFFORD TO WORK? CHILDCARE COSTS, TAX-BENEFIT POLICIES AND WORK INCENTIVES (2005)

Herwig Immervoll and David Barber

No. 30 CHALLENGES FACING LABOUR OFFICES AND SOCIAL INSURANCE (2005)

Anders Reutersward

No. 29 NET SOCIAL EXPENDITURE, 2005 EDITION

Willem Adema \& Maxime Ladaique

No. 28 WELFARE REFORM IN EUROPEAN COUNTRIES: A MICROSIMULATION ANALYSIS (2005)

Herwig Immervoll, Henrik Jacobsen Kleven, Claus Thustrup Kreiner and Emmanuel Saez

No. 27 TRENDS AND DETERMINANTS OF FERTILITY RATES: THE ROLE OF POLICIES (2005)

Cristina d'Addio \& Marco Mira d'Ercole

No. 26 THE “ENABLING STATE?” (2005)

Neil Guilbert

No. 25 COUNTING IMMIGRANTS AND EXPATRIATES IN OECD COUNTRIES: A NEW PERSPECTIVE (2005)

Jean-Christophe Dumont and Georges Lemaître

No. 24 TAXATION, ETHNIC TIES AND THE LOCATION CHOICE OF HIGHLY SKILLED IMMIGRANTS

(2005)

Thomas Liebig and Alfonso Sousa-Poza

No. 23 SHOULD WE EXTEND THE ROLE OF PRIVATE SOCIAL EXPENDITURE? (2005)

Mark Pearson and John P. Martin

No. 22 INCOME DISTRIBUTION AND POVERTY IN OECD COUNTRIES IN THE SECOND HALF OF THE $1990 S$ (2005)

Michael Förster and Marco Mira d'Ercole

No. 21 DESIGN CHOICES IN MARKET COMPETITION FOR EMPLOYMENT SERVICES FOR THE LONGTERM UNEMPLOYED (2004)

Ludo Struyven

No. 20 BENEFIT COVERAGE RATES AND HOUSEHOLD TYPOLOGIES: SCOPE AND LIMITATIONS OF TAX-BENEFIT INDICATORS (2004)

Herwig Immervoll, Pascal Marianna and Marco Mira D'Ercole

No. 19 AVERAGE AND MARGINAL EFFECTIVE TAX RATES FACING WORKERS IN THE EU. A MICROLEVEL ANALYSIS OF LEVELS, DISTRIBUTIONS AND DRIVING FACTORS (2004)

Herwig Immervoll

No. 18 INDICATORS OF UNEMPLOYMENT AND LOW-WAGE TRAPS (Marginal Effective Tax Rates on Employment Incomes) (2004)

Giuseppe Carone, Herwig Immervoll, Dominique Paturot and Aino Salomäki

No. 17 TAKE-UP OF WELFARE BENEFITS IN OECD COUNTRIES: A REVIEW OF THE EVIDENCE (2004)

Virginia Hernanz, Franck Malherbet and Michele Pellizzari

Recent available working papers can be found on the OECD website: http://www.oecd.org/els/workingpapers.

Other series of working papers available from the OECD include: OECD HEALTH WORKING PAPERS 


\section{RECENT RELATED OECD PUBLICATIONS:}

BABIES AND BOSSES: Reconciling Work and Family Life, Volume 4 Canada, Finland, Sweden and the United Kingdom (2005)

PENSIONS AT A GLANCE: Public policies across OECD countries (2005)

EXTENDING OPPORTUNITIES - How active social policy can benefit us all (2005)

SOCIETY AT A GLANCE: OECD Social Indicators (2005)

OECD EMPLOYMENT OUTLOOK (2005)

AGEING AND EMPLOYMENT POLICIES: AUSTRALIA (2005)

AGEING AND EMPLOYMENT POLICIES: AUSTRIA (2005)

AGEING AND EMPLOYMENT POLICIES: CANADA (2005)

AGEING AND EMPLOYMENT POLICIES: DENMARK (2005)

AGEING AND EMPLOYMENT POLICIES: FRANCE (2005)

AGEING AND EMPLOYMENT POLICIES: GERMANY (2005)

AGEING AND EMPLOYMENT POLICIES: NETHERLANDS (2005)

AGEING AND EMPLOYMENT POLICIES: UNITED STATES (2005)

PROMOTING ADULT LEARNING (2005)

MIGRATION, REMITTANCES AND DEVELOPMENT (2005)

TRENDS IN INTERNATIONAL MIGRATION: SOPEMI (2004)

MIGRATION FOR EMPLOYMENT: BILATERAL AGREEMENTS AT A CROSSROADS (2004)

INCOME DISPARITIES IN CHINA: AN OECD PERSPECTIVE (2004)

BENEFITS AND WAGES: OECD Indicators (2004)

REFORMING PUBLIC PENSIONS: SHARING THE EXPERIENCES OF TRANSITION AND OECD COUNTRIES (2004)

BABIES AND BOSSES: Reconciling Work and Family Life, Volume 3, New Zealand, Portugal, Switzerland (2004)

ASSET BUILDING AND THE ESCAPE FROM POVERTY: A NEW WELFARE POLICY DEBATE (2003)

MANAGING DECENTRALISATION: A NEW ROLE FOR LABOUR MARKET POLICY (2003)

COMBATING CHILD LABOUR: A REVIEW OF POLICIES (2003)

BABIES AND BOSSES: Reconciling Work and Family Life, Volume 2, Austria, Ireland and Japan (2003)

TRANSFORMING DISABILITY INTO ABILITY: Policies to Promote Work and Income Security for Disabled People (2003)

For a full list, consult the OECD On-Line Bookstore at www.oecd.org 